\title{
Flow processes near smooth and rough (concave) outer banks in curved open channels
}

\author{
K. Blanckaert, ${ }^{1,2}$ A. Duarte, ${ }^{2}$ Q. Chen, ${ }^{1}$ and A. J. Schleiss ${ }^{2}$ \\ Received 10 March 2012; revised 13 September 2012; accepted 17 September 2012; published 3 November 2012.
}

[1] Flow processes near the (concave) outer bank in curved river reaches are investigated in a laboratory flume, with focus on the influence of the bank roughness. An outer-bank cell of reversed secondary flow occurs for all the investigated roughness configurations of the outer bank. The cell widens the outer-bank boundary layer, which reduces the flow forcing on the bank, but also advects high-momentum fluid toward the lower part of the bank, which enhances the flow forcing on the bank. Increasing the roughness of the outer bank causes a considerable widening and strengthening of the outer-bank cell, which amplifies both effects on the flow forcing. The widening of the outer-bank boundary layer induced by the outer-bank cell reduces the effective width of the channel, i.e., the width where most of the discharge is conveyed, which increases significantly the sediment transport capacity in the central part of the channel. The near-bank processes are qualitatively similar but show considerable quantitative variations around the bend. The outer-bank cell reaches its maximum strength in the zone that is most vulnerable to bed scour and bank erosion, which corroborates its morphological relevance. The outer cell is mainly generated by reversed near-surface gradients in the profile of the streamwise velocity. The anisotropy of the cross-stream turbulence is the major mechanism opposed to the outer-bank cell. Increasing roughness of the outer bank amplifies all dominant mechanisms but does not modify their relative importance. The relevance of the experimental results for natural curved river configurations is discussed.

Citation: Blanckaert, K., A. Duarte, Q. Chen, and A. J. Schleiss (2012), Flow processes near smooth and rough (concave) outer banks in curved open channels, J. Geophys. Res., 117, F04020, doi:10.1029/2012JF002414.

\section{Introduction}

[2] In spite of their importance with respect to bank erosion, river planform dynamics, bank protection, and hazard mitigation, hydrodynamic processes near the (concave) outer bank in curved open channels are still poorly understood. These lacunas can largely be attributed to the scarcity of detailed experimental data. Models for the protection and the erosion of the outer bank in open-channel bends are generally based on a simplified parameterization of the flow forcing on the bank by means of an excess velocity, an excess bed shear stress at the toe of the bank, an excess bank shear stress and/or an excess flow depth [e.g., Ikeda et al., 1981; Thorne, 1982; Thorne et al., 1995; Darby and

\footnotetext{
${ }^{1}$ State Key Laboratory of Urban and Regional Ecology, Research Centre for Eco-Environmental Sciences, Chinese Academy of Sciences, Beijing, China.

${ }^{2}$ Laboratory of Hydraulic Constructions, École Polytechnique Fédérale de Lausanne, Lausanne, Switzerland.

Corresponding author: K. Blanckaert, State Key Laboratory of Urban and Regional Ecology, Research Centre for Eco-Environmental Sciences, Chinese Academy of Sciences, 100085 Beijing, China.

(koen.blanckaert@epfl.ch)

(C)2012. American Geophysical Union. All Rights Reserved. 0148-0227/12/2012JF002414
}

Thorne, 1996; Simon et al., 2000; Rinaldi and Darby, 2005; Rinaldi et al., 2008]. Thorne et al. [1995] summarize empirical and analytical models for the excess velocity and flow depth and conclude that they are highly inaccurate and only valid for mildly curved bends. Moreover these models do not account for characteristics of the outer bank such as its roughness. This paper aims at enhancing insight on the flow processes near the outer bank, and on the influence of the bank roughness. Enhancing insight is required to improve modeling of the flow forcing on the outer bank.

[3] A prominent flow feature near the outer bank of openchannel bends that largely conditions the near-bank hydrodynamics is the so-called outer-bank cell of secondary flow, which has a sense of rotation opposite to the curvatureinduced center-region cell of secondary flow. In this paper, we define secondary flow as the flow component perpendicular to the channel axis. Figure 1 conceptually represents flow in open-channel bends, including both cells of secondary flow. The outer-bank cell has been observed in previous laboratory experiments [e.g., Mockmore, 1943; Einstein and Harder, 1954; Rozovskii, 1957] and field investigations [e.g., Bathurst et al., 1977; Bridge and Jarvis, 1977; Bathurst et al., 1979; Thorne and Hey, 1979; de Vriend and Geldof, 1983]. Recent advances in measuring techniques and computational capacity have allowed for the 


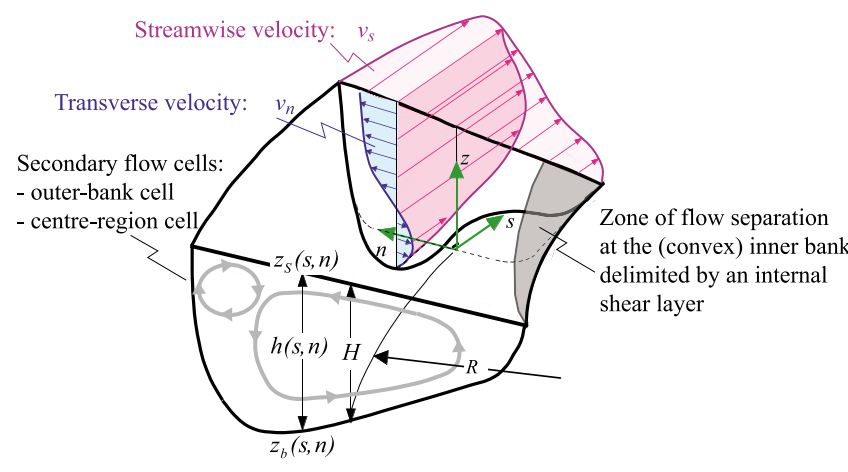

Figure 1. Conceptual representation of the characteristic features of open-channel bends. Modified from Blanckaert and de Vriend [2003]. The orthogonal $(s, n, z)$ reference system has its streamwise $s$ axis along the centerline, outward $n$ axis and vertically upward $z$ axis, and corresponding velocity component $\left(v_{s}, v_{n}, v_{z}\right)$. The variables $z_{S}$ and $z_{b}$, are the local water surface and bed elevations, respectively, and their difference defines the local flow depth $h$. The crosssectional averaged flow depth is $H$, and $R$ is the radius of curvature of the centerline.

detailed measurement of the outer-bank cell [Blanckaert and Graf, 2001; Booij, 2003; van Balen et al., 2009, 2010; Jamieson et al., 2010; Blanckaert, 2011; Termini and Piraino, 2011], its successful numerical simulation by means of three-dimensional (3D) large-eddy simulation (LES) codes [Booij, 2003; van Balen et al., 2009, 2010; Stoesser et al., 2010; Kang and Sotiropoulos, 2011] and the analysis of the mechanisms underlying these patterns based on the experimental and numerical data [Blanckaert and de Vriend, 2004; van Balen et al., 2009, 2010].

[4] With the exception the numerical simulations of Kang and Sotiropoulos [2011], all other contributions were, however, limited to configurations with a smooth vertical outer bank, which may not be representative for natural or canalized open-channel bends. Natural riverbanks are typically rough due to the presence of vegetation or trunks, local bank erosion, or the presence of slump blocks. Banks of canalized rivers are often protected with rough riprap. Jin et al. [1990] and Thorne and Furbish [1995] have investigated the effect of bank roughness in open-channel bends, but their spatial resolution was not sufficient to visualize near-bank patterns of secondary flow. Moreover, the numerical investigation of the influence of the outer bank roughness is not straightforward. Patel [1998] indicated that the simulation of flow at high Reynolds number and over rough surfaces is the Achilles heel of Computational Fluid Dynamics (CFD). Only recently 3D-LES simulations have been applied to shallow open-channel flows over rough beds [Stoesser and Rodi, 2004; Keylock et al., 2005; Hardy et al., 2007; McCoy et al., 2007; Stoesser et al., 2008; van Balen et al., 2009, 2010; Stoesser, 2010; Constantinescu et al., 2011a, 2011b; Koken and Constantinescu, 2011; Kang and Sotiropoulos, 2011]. But these simulations have focused on the bed roughness and 3D LES codes have not yet been validated for the simulation of the hydrodynamics near rough banks in shallow flows.

[5] In this paper, detailed measurements of flow in an experimental curved channel are presented and discussed. The purposes of the experiments are to (1) investigate the influence of the roughness of the outer bank on the flow processes near the outer bank, and especially on the outerbank cell of secondary flow; (2) investigate the evolution of these near-bank processes around a curved open-channel reach, (3) analyze the morphological implications of these near-bank processes, and of the influence of bank roughness; and (4) provide benchmark data for the validation on numerical models.

\section{The Experiments}

[6] Blanckaert [2010] reports in detail the experimental setup, the instruments, the data treatment procedures and estimates of the experimental uncertainty. In order to make the present paper self-contained, essential information is summarized immediately below. The present paper adopts the same nomenclature as Blanckaert [2010].

[7] The laboratory open-channel flume consists of a $9 \mathrm{~m}$ long straight entry reach, followed by a $193^{\circ}$ bend with constant centerline radius of curvature of $R=1.7 \mathrm{~m}$ and a $5 \mathrm{~m}$ long straight exit reach. The flume has vertical banks and a constant width of $B=1.3 \mathrm{~m}$. The bed of the flume is transversally horizontal and consists of glued uniform sand of $d=0.002 \mathrm{~m}$. The straight entry reach has a streamwise bed slope of 0.0022 , whereas the bed in the bend and the exit reach is horizontal. The inner bank is made of smooth PVC. Three roughness configurations of a vertical outer bank are investigated: a PVC bank that is smoother than the bed, a sand bank that is as rough as the bed, and a gravel bank that is rougher than the bed. The former is representative of banks protected with concrete lining, whereas the latter is representative of banks protected with riprap or irregularly shaped natural banks.

[8] Table 1 summarizes the geometric and hydraulic conditions of the three experiments, which all concern sharply

Table 1. Hydraulic and Geometric Conditions ${ }^{\mathrm{a}}$

\begin{tabular}{|c|c|c|c|c|c|c|c|c|c|c|c|c|c|}
\hline Label & $Q\left(1 \mathrm{~s}^{-1}\right)$ & $\tilde{H}(\mathrm{~m})$ & $\tilde{U}\left(\mathrm{~m} \mathrm{~s}^{-1}\right)$ & $E_{s, 0}\left(10^{-4}\right)$ & $C_{f, 0}^{-1 / 2}$ & $E_{s}\left(10^{-4}\right)$ & $C_{f}^{-1 / 2}$ & $\operatorname{Re}\left(10^{3}\right)$ & $F r$ & $R / B$ & $R / \tilde{H}$ & $B / \tilde{H}$ & $k_{s, \text { bank }}(\mathrm{m})$ \\
\hline F_16_90_00 & 89 & 0.159 & 0.43 & 6.2 & 14.7 & 8.5 & 13.2 & 69 & 0.34 & 1.31 & 10.7 & 8.2 & smooth \\
\hline F_16_90_02 & 89 & 0.159 & 0.43 & 6.8 & 14.2 & 10.1 & 12.1 & 69 & 0.34 & 1.31 & 10.7 & 8.2 & 0.002 \\
\hline F_16_90_30 & 89 & 0.155 & 0.44 & 8.2 & 13.2 & 14.5 & 10.5 & 69 & 0.36 & 1.31 & 11.0 & 8.4 & 0.030 \\
\hline
\end{tabular}

${ }^{\mathrm{a}} Q$ is the flow discharge; $\tilde{H}$ is the flume-averaged flow depth; $\tilde{U}=Q /(B \tilde{H})$ the flume averaged velocity; $E_{s, 0}$ is the average energy slope in straight inflow; $C_{f, 0}$ is the dimensionless Chézy friction coefficient for the straight inflow, defined as $C_{f, 0}^{-1 / 2}=U_{0} / \sqrt{g R_{h, 0}, E_{s, 0}}$, based on the average hydraulic radius $R_{h, 0}$ and velocity $U_{0}$ in the straight inflow reach; $E_{s}$ is the flume-averaged energy slope; $C_{f}$ is the dimensionless Chézy friction coefficient, defined as $C_{f}^{-1 / 2}=\tilde{U} / \sqrt{g \tilde{R}_{h} E_{s}}$, based on flume averaged flow characteristics; Re $=\tilde{U} \tilde{H} / \nu$ the Reynolds number; $F r=\tilde{U} / \sqrt{g \tilde{H}}$ the Froude number; $B$ is the flume width; $k$, banks is the roughness diameter of the outer bank material. 
curved $(R / \tilde{H} \approx 11$ and $R / B=1.31 ; \tilde{H}$ is the flume-averaged flow depth), subcritical (Froude number $\mathrm{Fr}<1$ ) openchannel flow.

[9] The curvature of open-channel bends is commonly parameterized by means of the ratio $R / B$ [e.g., Hickin, 1974; Markham and Thorne, 1992; Hooke, 2003]. This ratio tends to infinity for straight rivers, and reaches values lower than 1 for the sharpest bends occurring in nature (see compilation of field data in the work by Crosato [2008]). Although no objective criterion exists, the discriminator between moderately and sharply curved open-channel bends is commonly defined at a value of about $R / B=2$. The choice of sharp bends for the investigation of the near bank hydrodynamic processes is motivated by the facts that (1) knowledge of hydrodynamics and morphodynamics is particularly inaccurate for sharp bends [Thorne et al., 1995] and (2) the outer-bank cell, which will be shown to be the key to understanding the influence of the outer-bank roughness, amplifies with increasing bend sharpness [Blanckaert, 2011].

[10] The present paper adopts an orthogonal $(s, n, z)$ reference system with the streamwise $s$ axis along the centerline, outward $n$ axis and vertically upward $z$ axis (Figure 1). The discharge was measured with an uncertainty of about $1 \%$ by means of an electromagnetic flowmeter on the supply pipeline. Measurements of the bed and the water surface topography were made by means of echo sounders that are characterized by an uncertainty of less than $1 \mathrm{~mm}$. Velocity measurements were made by means of an Acoustic Doppler Velocity Profiler (ADVP) developed at the École Polytechnique Fédérale Lausanne, Switzerland [Lemmin and Rolland, 1997; Hurther and Lemmin, 1998; Blanckaert and Lemmin, 2006]. This instrument measures the 3D velocity vector with high spatial and temporal resolution simultaneously in an entire vertical profile. The sampling frequency was $31.25 \mathrm{~Hz}$ and the acquisition time was $180 \mathrm{~s}$. Blanckaert [2010] reports the following estimates of the uncertainty in the experimental data: $4 \%$ in the streamwise mean velocity $v_{s}, 10 \%$ in the transverse and vertical mean velocities $\left(v_{n}, v_{z}\right), 15 \%$ in the turbulent shear stresses $\left(\overline{v_{s}^{\prime} v_{n}^{\prime}}, \overline{v_{s}^{\prime} v_{z}^{\prime}}, \overline{v_{n}^{\prime} v_{z}^{\prime}}\right), 20 \%$ in the turbulent normal stresses $\left(\overline{v_{s}^{\prime 2}}, \overline{v_{n}^{\prime 2}}, \overline{v_{z}^{\prime 2}}\right)$, and $20 \%$ in the turbulent kinetic energy $(t k e)$ $k=0.5\left(\overline{v_{s}^{\prime 2}}+\overline{v_{n}^{\prime 2}}+\overline{v_{z}^{\prime 2}}\right)$. Blanckaert and de Vriend [2004] have estimated the uncertainty in quantities derived from the time-averaged velocities and turbulent stresses, yielding an uncertainty of $20 \%$ in the streamwise vorticity $\omega_{s}$, of about $40 \%$ in the different terms in the transport equation for streamwise vorticity and of about $50 \%$ in the transfer of kinetic energy between the mean flow and the turbulence. The streamwise vorticity is defined as

$$
\omega_{s}=\frac{\partial v_{z}}{\partial n}-\frac{\partial v_{n}}{\partial z}
$$

Near the bed the uncertainty in ADVP turbulence measurements is somewhat higher. The ADVP housing touches the water surface and causes perturbations in a layer of about $2 \mathrm{~cm}$ [Blanckaert, 2010], which is indicated by shading in all relevant figures. Measured data have been extrapolated in this layer with the unique objective of improving depth- averaged variables [Blanckaert, 2010]. The uncertainty in depth-averaged variables is less than $10 \%$.

[11] For each experiment, measurements were done in two steps. First, measurements were performed in the cross sections at $15^{\circ}, 30^{\circ}, 60^{\circ}, 90^{\circ}, 120^{\circ}, 150^{\circ}$ and $180^{\circ}$ in the bend on a grid with 11 equidistant vertical profiles from $n=-0.5 \mathrm{~m}$ to $n=+0.5 \mathrm{~m}$ (Figure 2). These measurements aimed at illustrating the global evolution of the flow and the near-bank processes around the bend, and at determining the most appropriate cross section for higher-resolution measurements. That cross section was subsequently measured on the refined grid indicated in Figure $3 \mathrm{~d}$ in order to analyze in detail the hydrodynamics. The spatial resolution of the measurements was higher in the smooth-bank experiments, where all cross sections were measured on the refined grid.

[12] In the present paper, mean flow quantities are normalized by the cross-stream-averaged velocity, $U=Q / B H$ ( $H$ is the cross-sectional-averaged flow depth). The turbulence quantities are normalized by the characteristic shear velocity for an equivalent straight uniform flow, defined as

$$
u_{*, 0}=C_{f, 0}^{1 / 2} U .
$$

Here $C_{f, 0}$ is the dimensionless Chézy friction coefficient for the straight inflow, defined as $C_{f, 0}^{-1 / 2}=U_{0} / \sqrt{g R_{h, 0}, E_{s, 0}}$, based on the average hydraulic radius $R_{h, 0}$, the average velocity $U_{0}$ and the average energy slope $E_{s, 0}$ in the straight inflow reach. The dense measuring grid allows estimating $E_{s, 0}$ with an uncertainty of less than $5 \%$, resulting in an uncertainty in $C_{f, 0}$ that is also about $5 \%$.

\section{Global Characteristics of the Flow and Identification of Near-Bank Hydrodynamic Processes}

[13] For all three investigated roughness configurations of the outer bank, the global flow field shows similar features, which are typical for (sufficiently long) singlebend configurations with transversally horizontal bed. These typical features have already been described and discussed by Zeng et al. [2008] for the smooth-bank experiment, and explained and modeled by Blanckaert and de Vriend [2003], Blanckaert [2009] and Blanckaert and de Vriend [2010]. They will be briefly reviewed below, since they are important for a global understanding of the hydrodynamics and allow identifying the hydrodynamic processes near the outer bank that will be investigated in sections 4-7.

[14] Figure 2 shows the evolution around the bend of the normalized depth-averaged streamwise vorticity, $\left\langle\omega_{s}\right\rangle H / U$, the normalized depth-averaged streamwise velocity, $U_{S} / U$, and the normalized depth-averaged tke, $\langle k\rangle / u_{*, 0}^{2}(\langle\rangle$ indicates depth-averaged variables), for the smooth-bank and rough-bank experiment. Similar figures for the sand-bank experiment are available in the work by Duarte [2008].

[15] The normalized depth-averaged streamwise vorticity, $\left\langle\omega_{s}\right\rangle H / U$, quantifies the evolution of the secondary flow (Figure 2a). The curvature-induced center-region cell of secondary flow grows from the bend entry to its maximum strength near the cross section at $90^{\circ}$ in the bend, and then decays gradually toward the bend exit. A zone of negative values of $\left\langle\omega_{s}\right\rangle H / U$ adjacent to the outer bank indicates the 

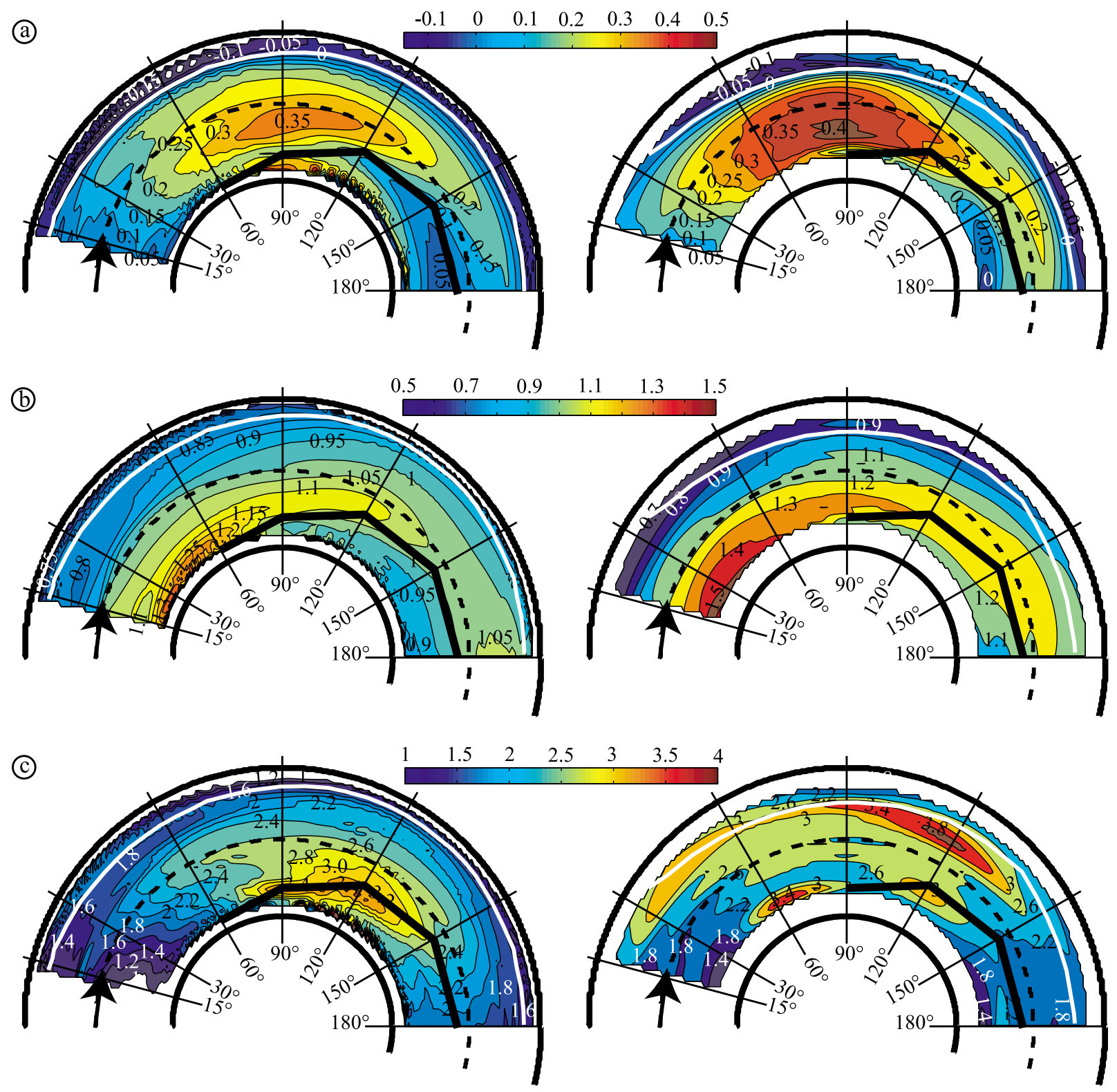

Figure 2. Global flow evolution around the bend in the smooth-bank (left column) and rough-bank (right column) experiments. Similar data for the sand-bank experiments is available in the work by Duarte [2008]. (a) Strength of the secondary flow, parameterized by means of the normalized depth-averaged streamwise vorticity $\left\langle\omega_{s}\right\rangle H / U$ (equation (1)); (b) normalized depth-averaged streamwise velocity, $U_{s} / U$; (c) normalized depth-averaged tke, $\langle k\rangle / u_{* 0}^{2}$. The patterns are interpolated between the measured cross sections, which are indicated by full lines. The white contour corresponding to $\left\langle\omega_{s}\right\rangle H / U=0$ indicates the separation between the center-region and outer-bank cells of secondary flow. The thick black line indicates the position of an internal shear layer separating retarded flow near the inner bank from the core of high velocities.

existence of an outer-bank cell of secondary flow with reversed sense of rotation.

[16] Near the cross section at $40^{\circ}$ in the bend, the flow cannot follow the strong curvature of the (convex) inner bank. The locus of highest velocities starts migrating outward and separates from the inner bank, and a zone of retarded flow occupies the region in between the inner bank and the core of highest velocities, as discernable in the pattern of the depth-averaged streamwise velocity $U_{s}$ (Figure $2 \mathrm{~b}$ ). This region of retarded flow widens in the streamwise direction.
An internal shear layer separates the zones of highest velocities and retarded flow. Near the outer bank, streamwise velocities are reduced in the region where the outer-bank cell of secondary flow occurs.

[17] Figure 2c shows the measured pattern of depthaveraged tke. According to Nezu and Nakagawa's [1993] semitheoretical distribution for straight open-channel flow, bed generated turbulence is characterized by a value of $\langle k\rangle / u_{*, 0}^{2}=2.07$. Curvature effects related to the secondary flow 

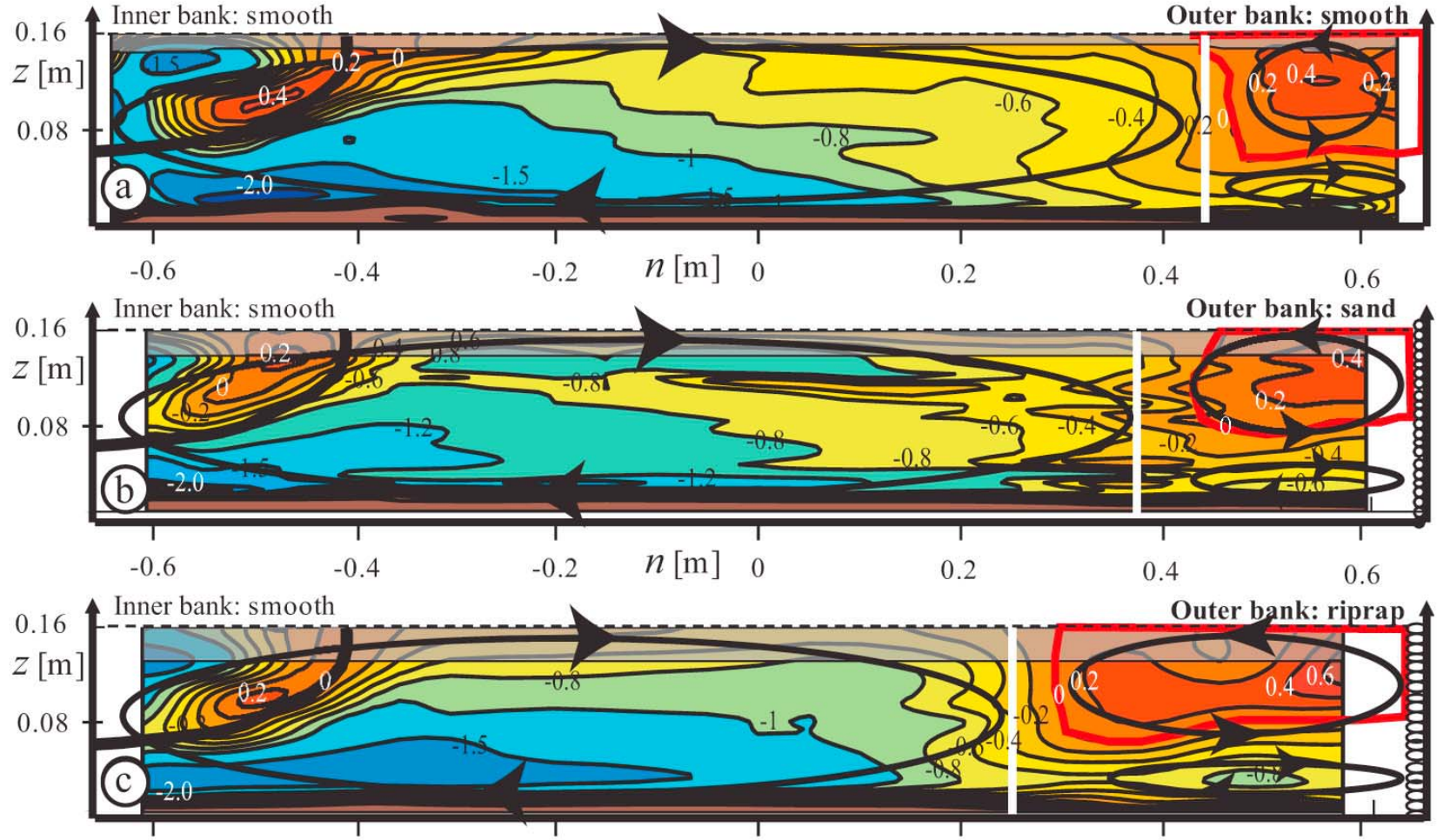
$-0.6$
$-0.4$
$-0.2 n[\mathrm{~m}] \quad 0$
0.2
0.4
0.6

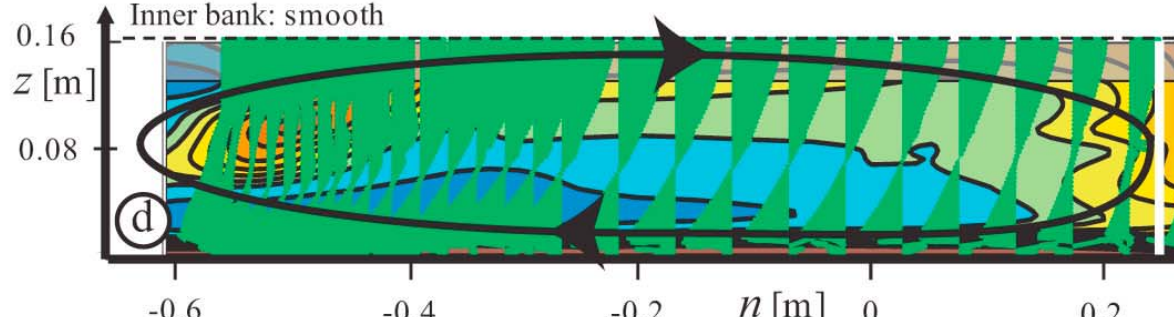
$-0.6$
$-0.4$
$-0.2 n[\mathrm{~m}] \quad 0$
0.2

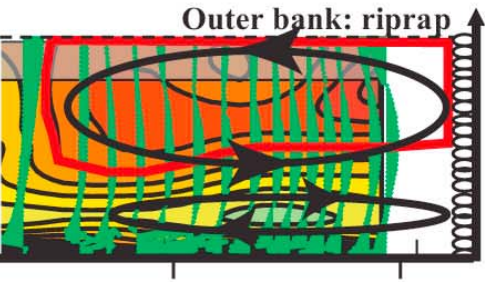

$0.16[\mathrm{~m}]$
0.08
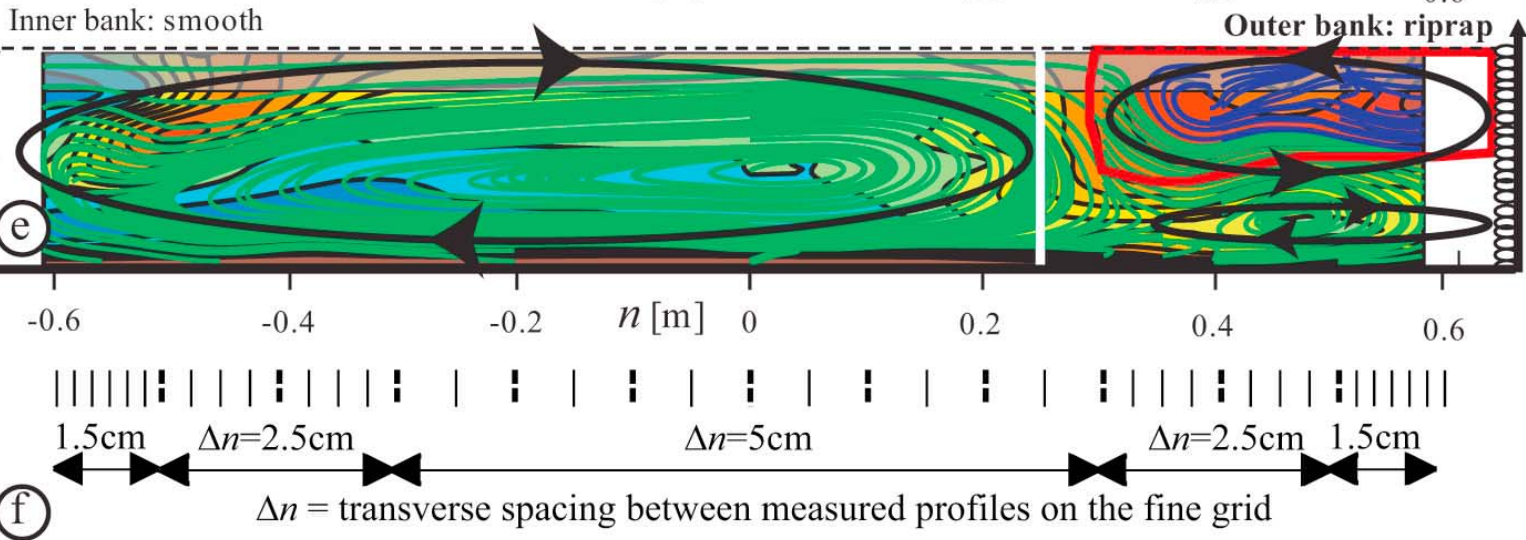

Figure 3. Isolines of the normalized streamwise vorticity $\omega_{s} H / U\left(\omega_{s}=\partial v_{z} / \partial n-\partial v_{n} / \partial z\right)$ in the cross section at $90^{\circ}$ in the (a) smooth-bank, (b) sand-bank and (c) riprap-bank experiments based on measurements performed with high spatial resolution. (d) Vector pattern $\left(v_{n}, v_{z}\right)$ and (e) streamlines of the secondary flow in the cross section at $90^{\circ}$ in the riprap-bank experiment. (f) Measuring grid. Schematic pattern of the center-region and outer-bank cells of secondary flow, whose separation is inferred from the core of maximum downwelling velocities (white vertical line) and the contour of zero streamwise vorticity (red contour). The same color bar is used in all figures. 

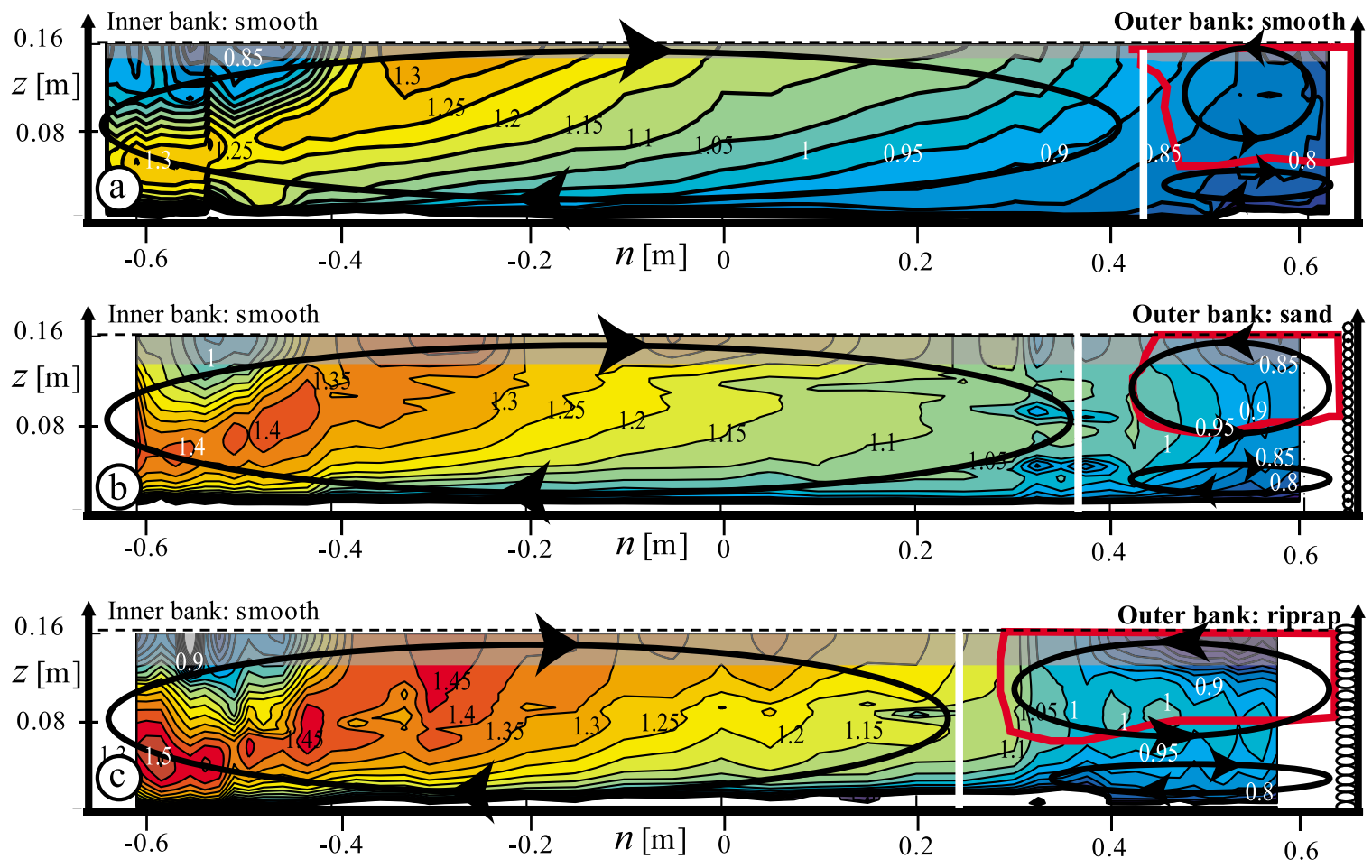

Figure 4. Isolines of the normalized streamwise velocity, $v_{s} / U$ in the cross section at $90^{\circ}$ in the (a) smooth-bank, (b) sand-bank, and (c) riprap-bank experiments. Schematic pattern of the center-region and outer-bank cells of secondary flow, whose separation is inferred from the core of maximum downwelling velocities (white vertical line) and the contour of zero streamwise vorticity (Figure 3, red contour). The same color bar is used in all figures.

considerably increase the the in the central part of the cross section, where maximum values of about $2.8 u_{*, 0}^{2}$ occur [Blanckaert, 2009]. Additional zones of increased tke occur near both banks. Their location coincides with the internal shear layer at the inner bank, and with the edge of the outerbank cell, respectively. This increased tke enhances the sediment transport capacity and hence has implications for the morphological development [van Prooijen and Winterwerp, 2010; Chang et al., 2011].

\section{Hydrodynamic Processes in the Cross Section at $90^{\circ}$ and Their Dependence on the Outer Bank Roughness}

[18] Measurements in the cross section at $90^{\circ}$ were performed with increased spatial resolution (measuring grid indicated in Figure 3). This cross section in the bend apex has been selected because the secondary flow is close to its maximum strength and tke shows a pronounced increase near the outer bank (Figure 2).

\subsection{Outer-Bank Cell of Reversed Secondary Flow}

[19] The streamwise vorticity, $\omega_{s}$ (equation (1)), is chosen to visualize and quantify the secondary flow cells, because it is a scalar, and it is governed by a transport equation that clearly reveals the underlying mechanisms [Blanckaert and de Vriend, 2004] (see further in section 5). The patterns of the normalized streamwise vorticity, $\omega_{s} H / U$, in the cross section at $90^{\circ}$ are qualitatively similar in all three experiments (Figure 3). This sharply curved bend is characterized by a strong center-region cell with maximum transverse velocities that attain values of about $v_{n} / U \approx 0.4$ and maximum vertical velocities of about $v_{z} / U \approx 0.05$ (not shown). The strength of the center-region cell is not significantly affected by the outer-bank roughness: the maximum value of $\omega_{s} H / U$ is similar at about $-2.2 \pm 0.2$ and the average value of $\omega_{s} H / U$ in the region occupied by the centerregion cell is similar at about $-0.75 \pm 0.05$ (differences are within the $20 \%$ experimental uncertainty). In all three experiments, an additional outer-bank cell with reversed sense of rotation occurs near the outer bank. It is weaker than the center-region cell, but amplifies and widens considerably with increasing roughness of the outer bank: the width increases from about $1.3 \mathrm{H}$ in the smooth-bank experiment, to about $1.7 \mathrm{H}$ in the sand-bank experiment, to about $2.5 \mathrm{H}$ in the riprap-bank experiment. Maximum values of $\omega_{s} H / U$ are about 0.44 in the smooth-bank experiment, 0.49 in the sand-bank experiment and 0.74 in the riprap-bank experiment. The average value of the $\omega_{s} H / U$ in the region occupied by the outer-bank cell is similar at about $0.19 \pm 0.03$.

[20] Figures $3 \mathrm{~d}$ and $3 \mathrm{e}$ show the vector pattern $\left(v_{n}, v_{z}\right)$ and the streamlines of the secondary flow, respectively, in the riprap-bank experiment. Both quantities provide similar information as the streamwise vorticity component shown in Figure $3 \mathrm{c}$, and clearly show the bicellular pattern of secondary flow. Henceforth, only the streamwise vorticity will be used to visualize the secondary flow pattern. To facilitate interpretation, the secondary flow pattern is schematically indicated in all relevant figures. The delimitation between 

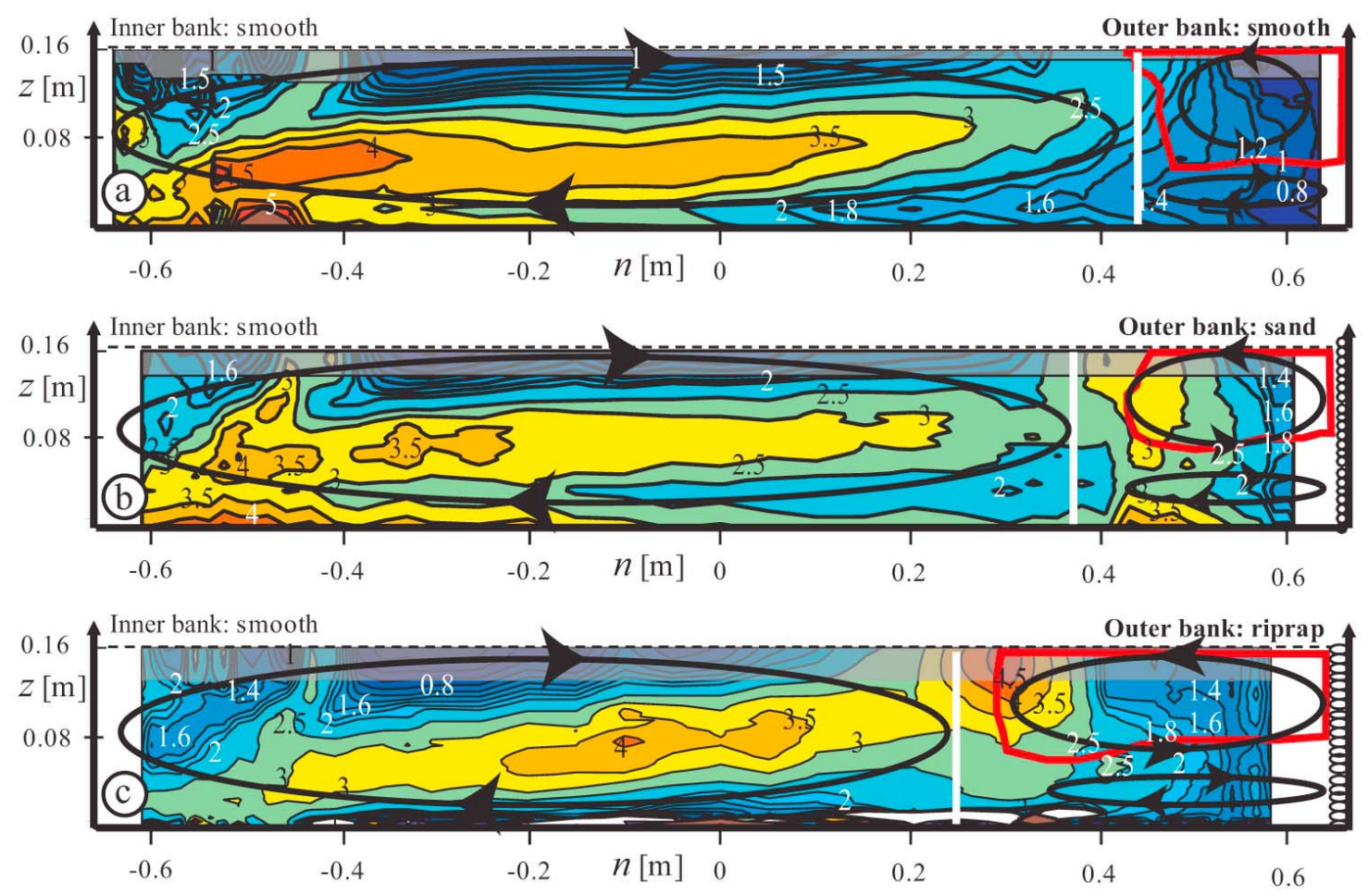

Figure 5. Isolines of the normalized turbulent kinetic energy, $k / u_{* 0}^{2}$, in the cross section at $90^{\circ}$ in the (a) smooth-bank, (b) sand-bank, and (c) riprap-bank experiments. Schematic pattern of the center-region and outer-bank cells of secondary flow, whose separation is inferred from the core of maximum downwelling velocities (white vertical line) and the contour of zero streamwise vorticity (Figure 3 , red contour). The same color bar is used in all figures.

the center-region cell and the outer-bank cell has been estimated from two criteria. First, it approximately coincides with the core of maximum downwelling vertical velocities (indicated by a white vertical line in the figures). Second, it is indicated by the $\omega_{s} H / U=0$ isoline (red contour in the figures). The latter furthermore shows that the outer-bank cell is restricted to the upper part of the water column and that a zone of opposite vorticity exists below the outer-bank cell. It is not clear if this zone concerns an additional secondary flow cell, or rather a protrusion of the center-region cell.

\subsection{Streamwise Flow}

[21] The secondary flow cells leave a strong footprint on the patterns of the normalized streamwise velocity, $v_{s} / U$, as illustrated for the cross section at $90^{\circ}$ in Figure 4. The center-region cell advects high-/low-momentum fluid in outward/inward direction in the upper/lower half of the water column, resulting in a net outward momentum transport. In single-bend configurations with transversally horizontal bed, this so-called "differential advection" is the main mechanism underlying the gradual outward shift of the core of highest velocities (Figure 2b) [Johannesson and Parker, 1989; Blanckaert and Graf, 2004]. It results in inclined $v_{s}$ isolines. Similarly, the counterrotating outer-bank cell causes an opposite differential advection in inward direction and an opposite inclination of the $v_{s}$ isolines. Figure 4 confirms that the $v_{s}$ isolines are nearly vertical in the upper part of the water column at the separation of both secondary flow cells.
The differential advection by the outer-bank cell widens the bank boundary layer and reduces the velocity gradients near the bank.

[22] Momentum advection by the outer-bank cell also modifies the vertical profiles of velocity, which are typically monotonously increasing from the bed to the surface in a straight uniform flow. The high velocities that originate near the water surface are advected toward the lower edge of the outer-bank cell, and replaced by low velocities originating near the bank. This results in a maximum velocity that is situated at about middepth, and a reversed vertical velocity gradient, $\partial v_{s} / \partial z<0$ in the upper part of the water column, which is known to play an important role in the generation of the outer-bank cell [Blanckaert and de Vriend, 2004; van Balen et al., 2010].

\subsection{Turbulence Characteristics}

[23] According to Nezu and Nakagawa [1993], bed generated turbulence in straight uniform open-channel flow is characterized by (1) a vertical profile that decreases exponentially from a maximum value of $k / u_{*, 0}^{2}=4.78$ at the bed toward the water surface, and by a depth-averaged value of 2.07; (2) similar distributions of the three turbulent normal stresses; and (3) a dominance of the streamwise turbulent normal stress with $\overline{v_{n}^{\prime 2}} / \overline{v_{s}^{\prime 2}}=0.51$ and $\overline{v_{z}^{\prime 2}} / \overline{v_{s}^{\prime 2}}=0.34$. Figures 5 and 6 clearly show that the secondary flow cells also leave a strong footprint on the turbulence characteristics, and they 

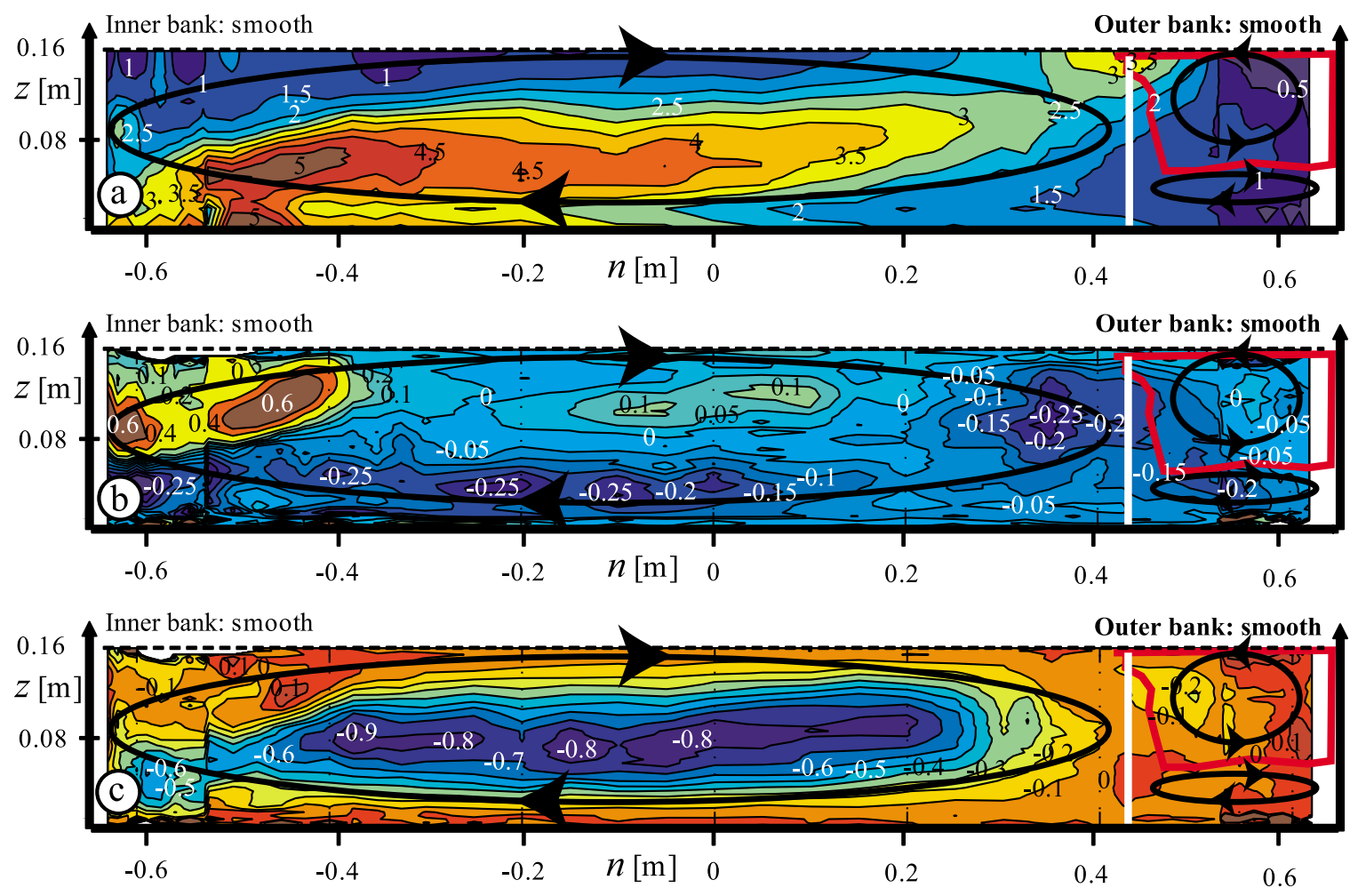

Figure 6. Isolines of the most relevant normalized turbulent normal stresses and shear stresses in the cross section at $90^{\circ}$ in the smooth-bank experiments: (a) $v_{n}^{\prime 2} / u_{*, 0}^{2}$, (b) $\overline{v_{s}^{\prime} v_{z}^{\prime}} / u_{*, 0}^{2}$, and (c) $\overline{v_{n}^{\prime} v_{z}^{\prime}} / u_{*, 0}^{2}$. Schematic pattern of the center-region and outer-bank cells of secondary flow, whose separation is inferred from the core of maximum downwelling velocities (white vertical line) and the contour of zero streamwise vorticity (Figure 3, red contour).

clearly identify hydrodynamic processes that generate additional curvature-induced turbulence.

[24] Blanckaert [2009] has explained the increase in tke occurring in the center-region cell of secondary flow (Figure 5), and successfully simulated it with a conceptual model. The present section, therefore, focuses on the region near the outer bank. A core of increased tke values occurs at the separation between the center-region cell and the outerbank cell of secondary flow. The tke decreases from this core of high values toward the outer bank. The roughening of the outer bank leads to a considerable increase in the maximum tke values at the separation of both secondary flow cells. But it also shifts these maximum values farther away from the bank due to the widening of the outer-bank cell.

[25] Figure 6 shows the patterns of the most relevant turbulent normal stresses and shear stresses for the smoothbank experiment. Patterns for the sand-bank and riprap-bank experiment show qualitatively similar features (not shown). The patterns of the turbulent normal stresses reveal that turbulence is highly anisotropic in sharply curved openchannel flow. Contrary to straight uniform open-channel flow, the transverse turbulent normal stress $\overline{v_{n}^{\prime 2}}$ is the dominant contribution to the tke (compare Figure 6a to Figure 5a). The curvature-induced increase in tke at the separation between the center-region and outer-bank cells (Figure 5a) is mainly due to high contributions of $\overline{v_{n}^{\prime 2}}$.
[26] Contrary to straight uniform open-channel flow where $\overline{v_{s}^{\prime} v_{n}^{\prime}}, \overline{v_{n}^{\prime} v_{\mathrm{z}}^{\prime}} \ll \overline{v_{s}^{\prime} v_{z}^{\prime}}$, all three turbulent shear stresses are of similar magnitude in curved open-channel flow (Figure 7). Similar to findings by Blanckaert and Graf [2001] in a sharply curved narrow laboratory flume with mobile bed, the outer-bank cell of secondary flow is clearly discernable in the pattern of the turbulent shear stress $\overline{v_{n}^{\prime} v_{z}^{\prime}}$. The near-bed values of $\overline{v_{s}^{\prime} v_{z}^{\prime}}$ and $\overline{v_{n}^{\prime} v_{z}^{\prime}}$ correspond to the streamwise and transverse component of the bed shear stress, respectively. Both components are of comparable magnitude in the region covered by the center-region cell, which implies that the bed shear stress has a strong inward component. This additional inward component considerably increases the sediment transport capacity as compared to a straight flow.

\section{Mechanisms Underlying the Outer-Bank Cell of Secondary Flow and Their Dependence on the Outer-Bank Roughness}

[27] The experimental data reveal that the outer-bank cell of secondary flow is the key process responsible for the widening of the outer-bank boundary layer, the reduction of near-bank velocities and the increase of near-bank tke when the roughness of the outer bank is increased. The present section focuses on the mechanisms underlying the outer- 

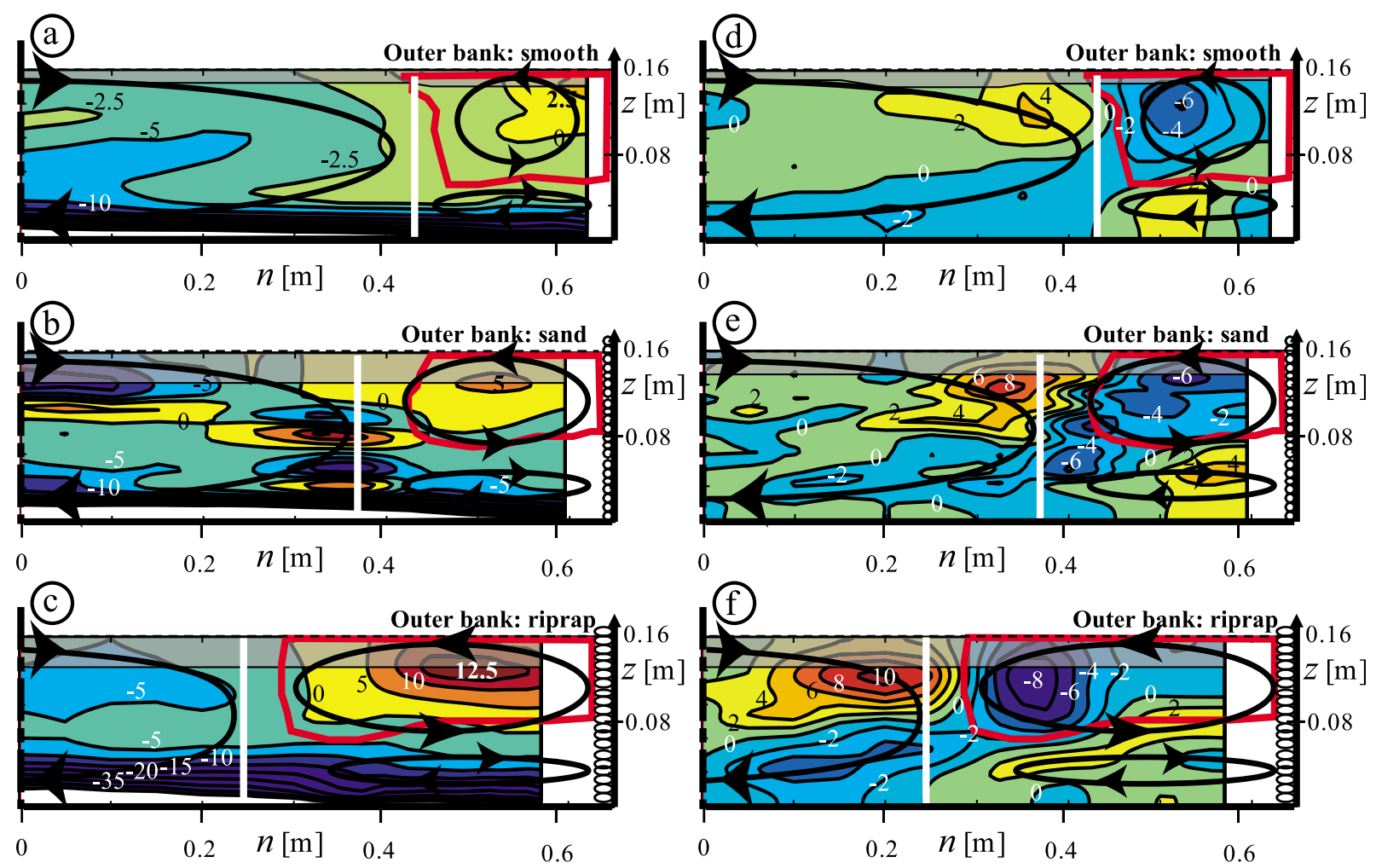

Figure 7. Isolines of the normalized centrifugal term, $100 \mathrm{CFG} /\left(U^{2} / H^{2}\right)$ (equation (3); left column), and the normalized turbulence anisotropy term, $100 \mathrm{ANIS} /\left(U^{2} / H^{2}\right)$ (equation (4); right column) in the outer half of the cross section at $90^{\circ}$ in the (a, d) smooth-bank, (b, e) sand-bank, and (c, f) riprap-bank experiments. Schematic pattern of the center-region and outer-bank cells of secondary flow, whose separation is inferred from the core of maximum downwelling velocities (white vertical line) and the contour of zero streamwise vorticity (Figure 3, red contour).

bank cell and their dependence on the roughness of the outer bank, by means of the same methodology that was recently applied by Blanckaert and de Vriend [2004] and van Balen et al. [2009, 2010] to investigate configurations with smooth vertical banks. These previous investigations were based on a term-by-term analysis of the transport equation for streamwise vorticity and the kinetic energy transfer between the mean flow and the turbulence. We refer to Blanckaert and de Vriend [2004] for the presentation and detailed discussion of these equations.

[28] These previous investigations pointed to the following generation mechanism of the outer-bank cell. First, the influence exerted by the outer bank and the water surface on the flow leads to a deformation of the vertical $v_{s}$ profiles, resulting in a negative velocity gradient $\partial v_{s} / \partial z<0$ in the upper part of the water column (Figure 4), which favors the generation of the outer-bank cell. This favorable effect is quantified by the centrifugal term in the transport equation for the streamwise vorticity [Blanckaert and de Vriend, 2004]:

$$
C F G=-\frac{1}{1+n / R} \frac{\partial}{\partial z}\left(\frac{v_{s}^{2}}{R}\right) .
$$

Second, cross-stream turbulence stresses, $\overline{v_{n}^{\prime 2}}, \overline{v_{z}^{\prime 2}}$ and $\overline{v_{n}^{\prime} v_{z}^{\prime}}$ play a dominant role, mainly by opposing the outer-bank cell. Their influence on the outer-bank cell is quantified by means of the following terms in the transport equation for streamwise vorticity [Blanckaert and de Vriend, 2004]:

$$
\begin{gathered}
A N I S=\frac{\partial^{2}}{\partial z \partial n}\left(\overline{v_{n}^{\prime 2}}-\overline{v_{z}^{\prime 2}}\right)+\frac{1}{1+n / R} \frac{1}{R} \frac{\partial \overline{v_{n}^{\prime 2}}}{\partial z}, \\
S H E A R=\left\{\frac{1}{1+n / R} \frac{\partial^{2}}{\partial z^{2}}-\frac{\partial}{\partial n}\left(\frac{1}{1+n / R} \frac{\partial}{\partial n}\right)\right\}\left[(1+n / R) \overline{v_{n}^{\prime} v_{z}^{\prime}}\right] .
\end{gathered}
$$

These previous investigations were not in complete agreement on the role of the terms "ANIS" and "SHEAR." For the three investigated roughness configurations, the terms "CFG," ANIS and SHEAR are of dominant order of magnitude in the region covered by the outer-bank cell, here called the "OBC region" (indicated by the $\omega_{s}=0$ contour in all figures). The term "SHEAR" contains positive and negative contributions that approximately cancel one another when integrated over the OBC region. For the sake of clarity and conciseness, Figure 7 only shows the patterns of the two dominant terms CFG and ANIS, as well as their dependence on the outer-bank roughness. For all roughness configurations, the patterns of CFG and ANIS show a clear relation to the outer-bank cell (Figure 3): the OBC region about coincides with a core of positive/negative values of CFG/ANIS and both terms change sign at the edge of the $\mathrm{OBC}$ region. 

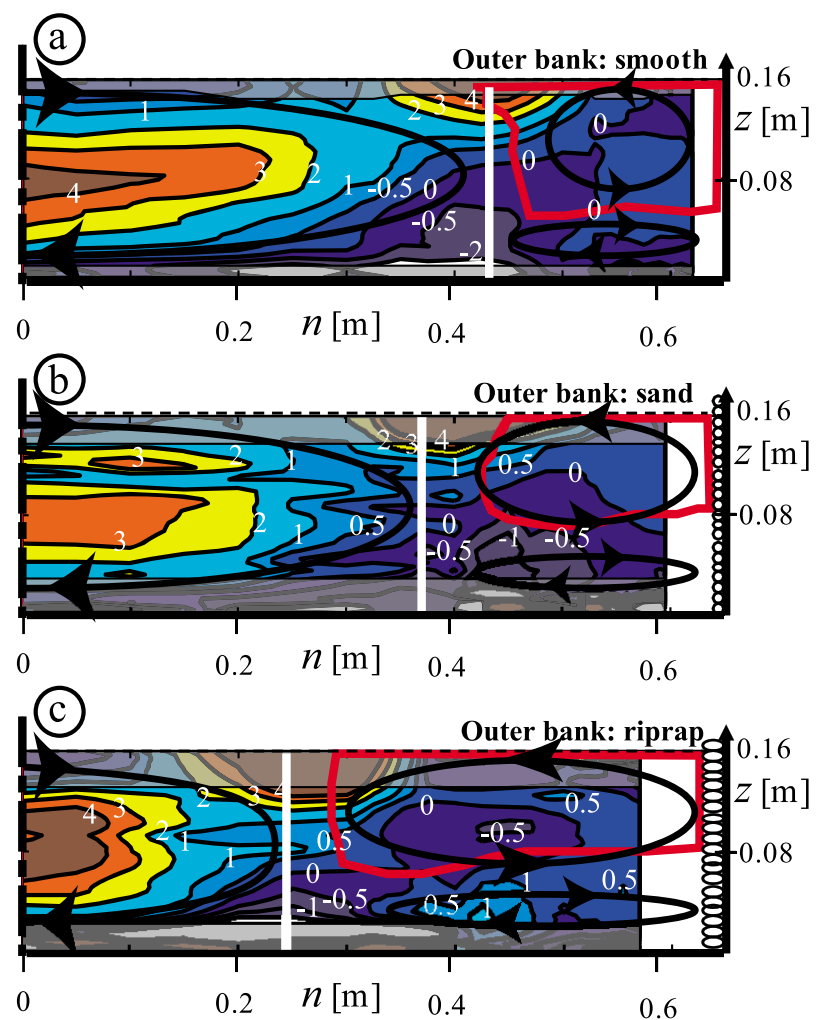

Figure 8. Isolines of the normalized kinetic energy transfer via the cross-stream turbulence, $\left(\mathscr{P}_{n n}+\mathscr{P}_{z z}+\mathscr{P}_{n z}\right) \kappa H / u_{*}^{3}$ (equation (6)) in the outer half of the cross section at $90^{*}$ in the (a) smooth-bank, (b) sand-bank, and (c) riprap-bank experiments. Schematic pattern of the center-region and outer-bank cells of secondary flow, whose separation is inferred from the core of maximum downwelling velocities (white vertical line) and the contour of zero streamwise vorticity (Figure 3, red contour).

When integrated over the $\mathrm{OBC}$ region, both terms are an order of magnitude larger than SHEAR.

[29] Blanckaert and de Vriend [2004] have argued that the kinetic energy transfer between the mean flow and the turbulence via the cross-stream turbulent stresses also plays an important role with respect to the generation of the outerbank cell. It is defined as [Hinze, 1975]

$$
\begin{aligned}
\mathscr{P}_{n n}+\mathscr{P}_{z z}+\mathscr{P}_{n z}= & \left(\overline{v_{n}^{\prime 2}}-\frac{2}{3} k\right)\left(\frac{\partial v_{n}}{\partial n}\right)+\left(\overline{v_{z}^{\prime 2}}-\frac{2}{3} k\right)\left(\frac{\partial v_{z}}{\partial z}\right) \\
& +\left(\overline{v_{n}^{\prime} v_{z}^{\prime}}\right)\left(\frac{\partial v_{z}}{\partial n}+\frac{\partial v_{n}}{\partial z}\right)
\end{aligned}
$$

They argued that a kinetic energy transfer from the mean flow to the turbulence, $\mathscr{P}_{n n}+\mathscr{P}_{z z}+\mathscr{P}_{n z}>0$, tends to dissipate the outer-bank cell. Previous results indicated that $\mathscr{P}_{n n}+\mathscr{P}_{z z}+\mathscr{P}_{n z}$ is small in the $\mathrm{OBC}$ region, and it is partially directed from turbulence to the mean flow, $\mathscr{P}_{n n}+\mathscr{P}_{z z}+\mathscr{P}_{n z}<0$. For the three investigated roughness configurations, $\mathscr{P}_{n n}+\mathscr{P}_{z z}+\mathscr{P}_{n z}$ (Figure 8), is indeed an order of magnitude smaller in the OBC region than in the region covered by the center-region cell and even contains negative contributions. Strong dissipation of mean flow kinetic energy occurs near the water surface at the edge of the outer-bank cell and the center-region cell.
[30] From this analysis, it can be concluded that the widening and strengthening of the outer-bank cell with increasing roughness of the outer bank (Figure 3 ) is explained by the widening and strengthening of the related cores of $\mathrm{CFG}$ and ANIS (Figure 7), and the widening of the region of low $\mathscr{P}_{n n}+\mathscr{P}_{z z}+\mathscr{P}_{n z}$ values (Figure 8 ). The roughening of the outer bank does not modify the relative importance of these different mechanisms and their interaction, but strengthens all of them.

\section{Evolution Around the Bend of Flow Processes Near the Outer Bank and Their Dependence on the Outer-Bank Roughness}

[31] The evolution of the outer-bank cell around the bend is illustrated in Figure 9 by means of the patterns of the normalized streamwise vorticity, $\omega_{s} H / U$ measured in the outer half of the cross sections at $15^{\circ}, 30^{\circ}, 60^{\circ}, 90^{\circ}, 120^{\circ}$, $150^{\circ}$ and $180^{\circ}$ in the bend. The left column shows the smooth-bank experiment, and the right column the riprapbank experiment. As aforementioned, all cross sections in the smooth-bank experiment were measured on a refined measuring grid, whereas only the cross section at $90^{\circ}$ in the riprap-bank experiment was measured on this refined grid. The lower spatial measuring resolution in the other cross section causes an increased uncertainty in the estimation of the streamwise vorticity (equation (1)).

[32] In all cross sections, the patterns of $\omega_{s} H / U$ are qualitatively similar and indicate the existence of a centerregion cell, an outer-bank cell of reversed secondary flow in the upper part of the water column near the outer bank, and a zone opposite vorticity below the outer-bank cell. The width and strength of the secondary flow cells vary considerably around the bend, and shows considerable differences between the smooth-bank and riprap-bank experiments.

[33] Similar to section 4.1, the width of the outer-bank cell has been estimated from two criteria: (1) the $\omega_{s} H / U=0$ isoline indicated by the red vertical line in Figure 9 and (2) the core of maximum downwelling vertical velocities (not shown) indicated by the white vertical line in Figure 9. Figures 9 and 10 indicate that the width of the outer-bank cell increases from the bend entry to about the cross section at $60^{\circ}$, and slightly decreases downstream of the bend apex. The width increases considerably with increasing bank roughness: averaged around the bend, the width of the outerbank cell is about $1.1 \mathrm{H}$ in the smooth-bank experiment and about $2.2 H$ in the riprap-bank experiment.

[34] Because of the irregularities in the patterns of the streamwise vorticity (Figure 9), the strength of the secondary flow cells is commonly quantified by means of averaged or integral quantities. Zeng et al. [2008] made use of the circulation of both secondary flow cells, defined as

$$
\Gamma_{i}=\iint_{A_{i}}\left(\omega_{s} H / U\right) d A_{i}
$$

$(i=O B C, C R C)$

where $A_{O B C}$ and $A_{C R C}$ stand for the cross-sectional area occupied by the outer-bank cell and the center-region cell, 

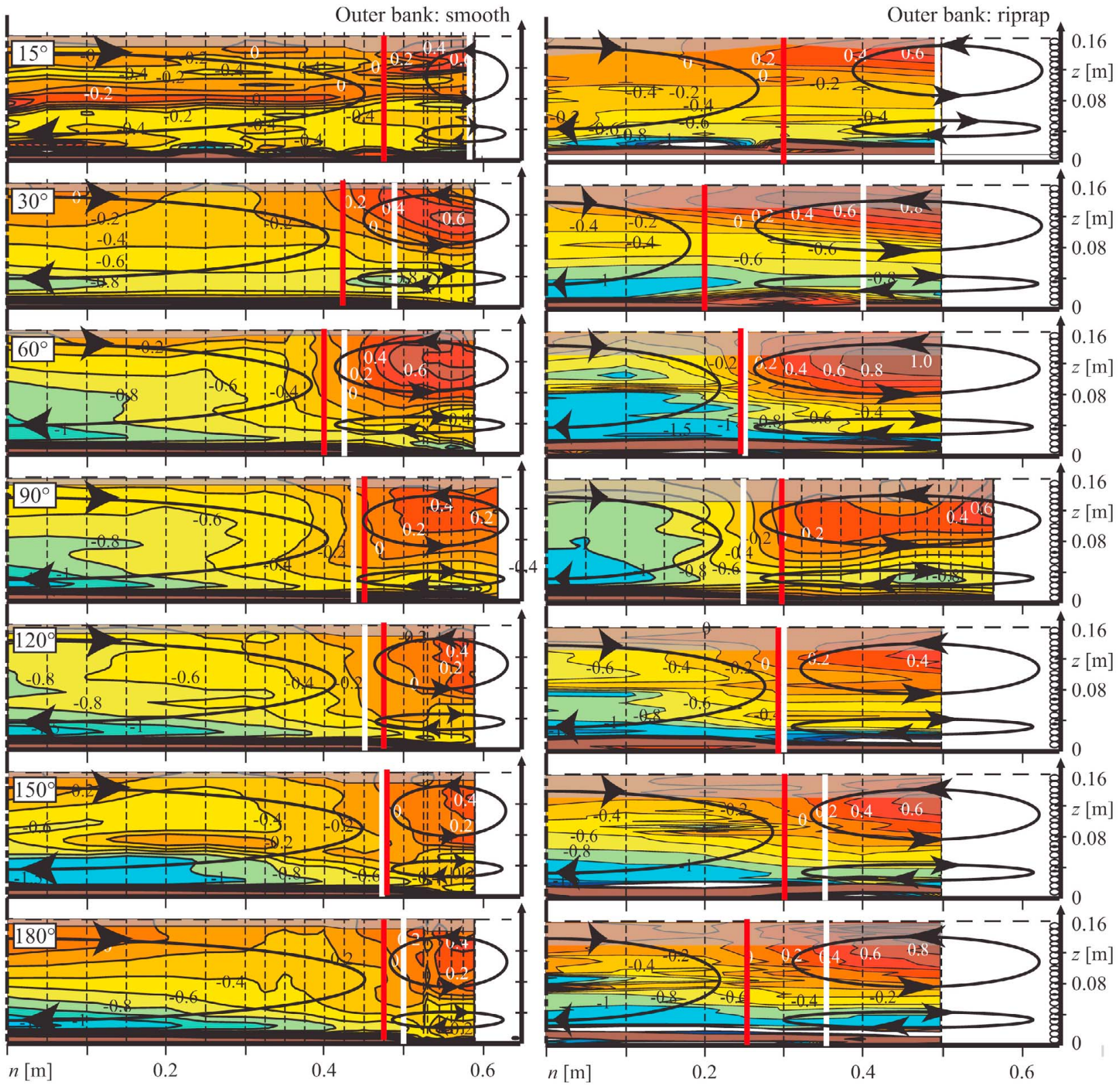

Figure 9. Isolines of the normalized streamwise vorticity $\omega_{s} H / U$ in the cross sections at $15^{\circ}, 30^{\circ}, 60^{\circ}$, $90^{\circ}, 120^{\circ}, 150^{\circ}$ and $180^{\circ}$ in the bend. (left) The smooth-bank experiment and (right) the riprap-bank experiment. Only the outer half of the cross sections is shown. The patterns include the measuring grid, a schematic representation of the center-region and outer-bank cells of secondary flow, whose separation is inferred from the core of maximum downwelling velocities (white vertical line and the contour of zero streamwise vorticity (red vertical line). The same color bar is used in all figures.

respectively. van Balen et al. [2010] used the normalized circulation:

$$
\left\langle\omega_{s} H / U\right\rangle_{i}=\frac{\Gamma_{i}}{A_{i}}=\frac{1}{A_{i}} \iint_{A_{i}}\left(\omega_{s} H / U\right) d A_{i}
$$

which represents by definition the average value of $\omega_{s} H / U$ in the region covered by the considered secondary flow cell. Figure 11 shows the evolution around the bend of $\left\langle\omega_{s} H / U\right\rangle_{i}$ for both secondary flow cells in the smooth-bank experiment.
As already noticed in Figure 2, the center-region cell strengthens from the bend entry to its maximum value near the cross section at $90^{\circ}$ in the bend, and then decays gradually toward the bend exit. The outer-bank cell strengthens in the initial part of the bend and reaches its maximum value near $60^{\circ}$ in the bend. Its strength remains about constant downstream from the bend apex. In the cross section at $90^{\circ}$, $\left\langle\omega_{s} H / U\right\rangle_{C R C}$ was slightly higher in the riprap-bank experiment than in the smooth-bank experiment, which can be attributed to the reduced width of the center-region cell. In 


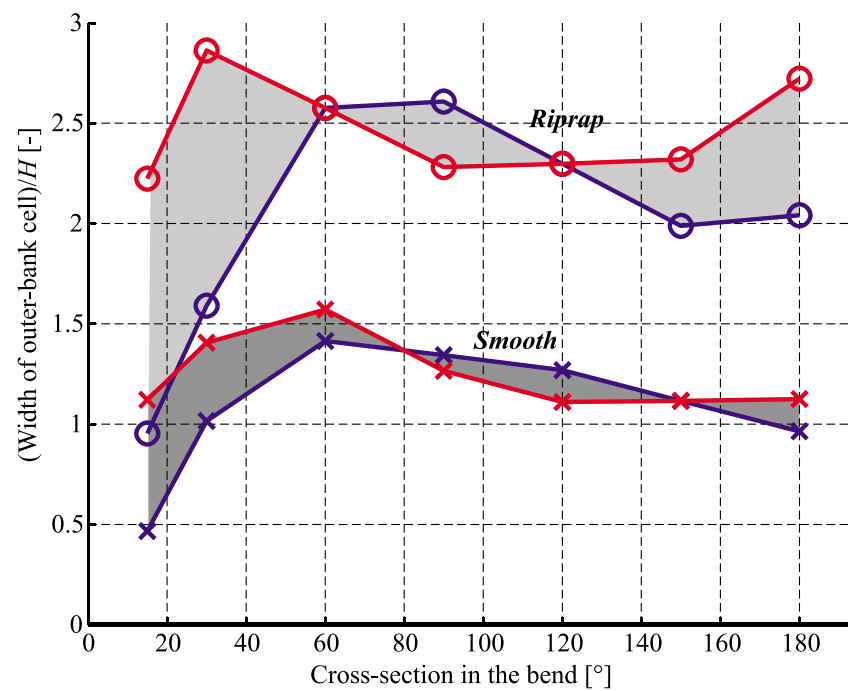

Figure 10. Evolution around the bend of the width of the outer-bank cell normalized by the averaged flow depth in the cross section in the smooth-bank (cross) and riprap-bank (circle) experiments. The blue data points correspond to the position of the white lines in Figure 9, and the red data points correspond to the position of the red lines in Figure 9.

the same cross section $\left\langle\omega_{s} H / U\right\rangle_{O B C}$ increased from 0.17 in the smooth-bank experiment to 0.21 in the riprap-bank experiment.

[35] In the riprap-bank experiment, the measuring grid in the cross sections at $15^{\circ}, 30^{\circ}, 60^{\circ}, 120^{\circ}, 150^{\circ}$ and $180^{\circ}$ was too coarse to allow for an accurate estimation of integral values according to equation (8). Figure 11 shows, however, a strong correlation between the average value $\left\langle\omega_{s} H / U\right\rangle_{O B C}$ and the maximum value $\left(\omega_{s} H / U\right)_{\max }$ of the vorticity in the outer-bank cell in the smooth-bank experiment. Hence, the influence of the bank roughness on the strength of the outerbank cell can be assessed by means of $\left(\omega_{s} H / U\right)_{\max }$. Figure 11 shows that values of $\left(\omega_{s} H / U\right)_{\max }$ are on the average about $50 \%$ higher in the riprap-bank experiment than in the smooth-bank experiment.

[36] The key role played by the outer-bank cell with respect to the near-bank flow processes and the influence of the outer-bank roughness are confirmed by the patterns of the normalized streamwise vorticity $\omega_{s} H / U$, streamwise velocity $v_{s} / U$ and turbulent kinetic energy $k / u_{*, 0}^{2}$ in the cross section at $150^{\circ}$ in the bend in the smooth-bank (Figure 12) and riprap-bank (Figure 13) experiments. These patterns are very similar to the corresponding patterns in the cross section at $90^{\circ}$, shown in Figures $3-5$. The cross section at $150^{\circ}$ has been selected because it is situated in the downstream part of the bend where the flow field has largely adapted to the constant curvature of the bend, and because it is not yet influenced by the suddenly vanishing curvature at the bend exit.

\section{Discussion}

\subsection{Morphological Implications}

[37] The outer-bank cell is known to play an important role with respect to the flow forcing on the outer bank, and hence the river morphodynamics [Blanckaert, 2011]. Its inward differential advection widens the outer-bank boundary layer (Figure 4) by confining maximum streamwise velocities toward the inner edge of the outer-bank cell. This decreases the near-bank velocity gradient and hence the flow forcing on the outer bank. But the outer-bank cell also advects high-momentum fluid originating from near the water surface toward the lower part of the outer bank (Figure 4), which tends to increase the flow forcing causing bank instability. Based on observations in a natural river, Bathurst et al. [1979] postulated that the second effect is dominant, whereas Blanckaert and Graf [2004] found the first effect to be dominant in a laboratory flume with mobile bed and smooth vertical banks. The results show that an increase in bank roughness leads to a considerable widening of the outer-bank cell, which strengthens the first protective mechanism. But the increase in bank roughness also increased the strength of the outer-bank cell and thus the advection of high-momentum fluid toward the bank. Results are not yet conclusive with respect to the influence of the bank roughness on the flow forcing on the outer bank. But the results clearly demonstrate the morphological relevance of the outer-bank roughness. These results also confirm and explain the widening of the outer-bank boundary layer with increasing roughness observed in field experiments by Thorne and Furbish [1995].

[38] The widening of the outer-bank boundary layer induced by the outer-bank cell reduces the effective width of the channel, i.e., the width where most of the discharge is conveyed. This is well illustrated by comparing the smoothbank and riprap-bank experiments: the widening of the outer-bank cell and the corresponding bank boundary layer from about $1.2 \mathrm{H}$ in the smooth-bank experiment to about $2.3 H$ in the riprap bank experiment causes a reduction in the

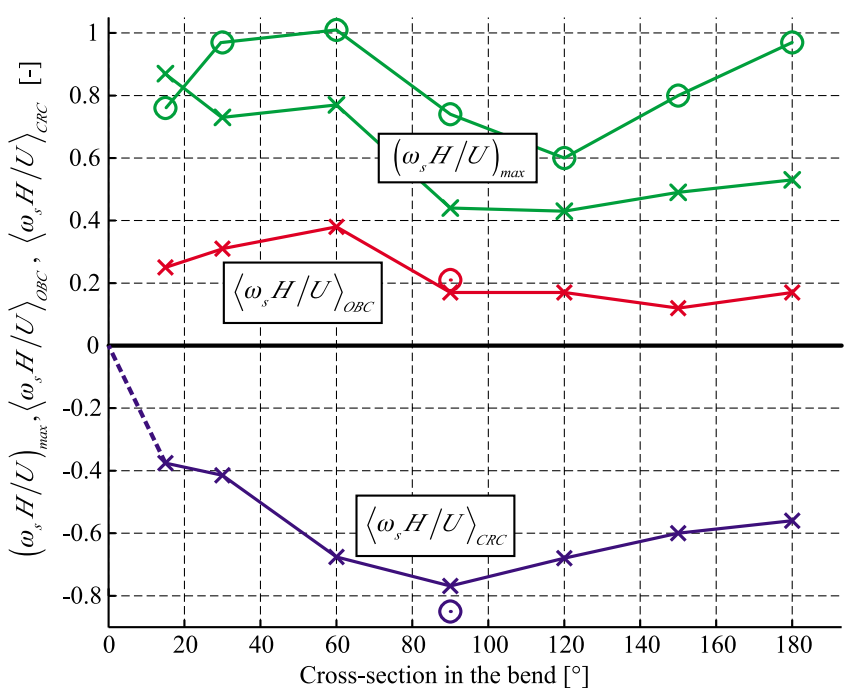

Figure 11. Evolution around the bend of the strength of the center-region cell (CRC) and outer-bank cell (OBC) in the smooth-bank (cross) and riprap-bank (circle) experiments. The strength is defined by means of the maximum (index max) and average $(\langle\rangle)$ value of the normalized streamwise vorticity $\omega_{s} H / U$ in the region covered by the secondary flow cell. 


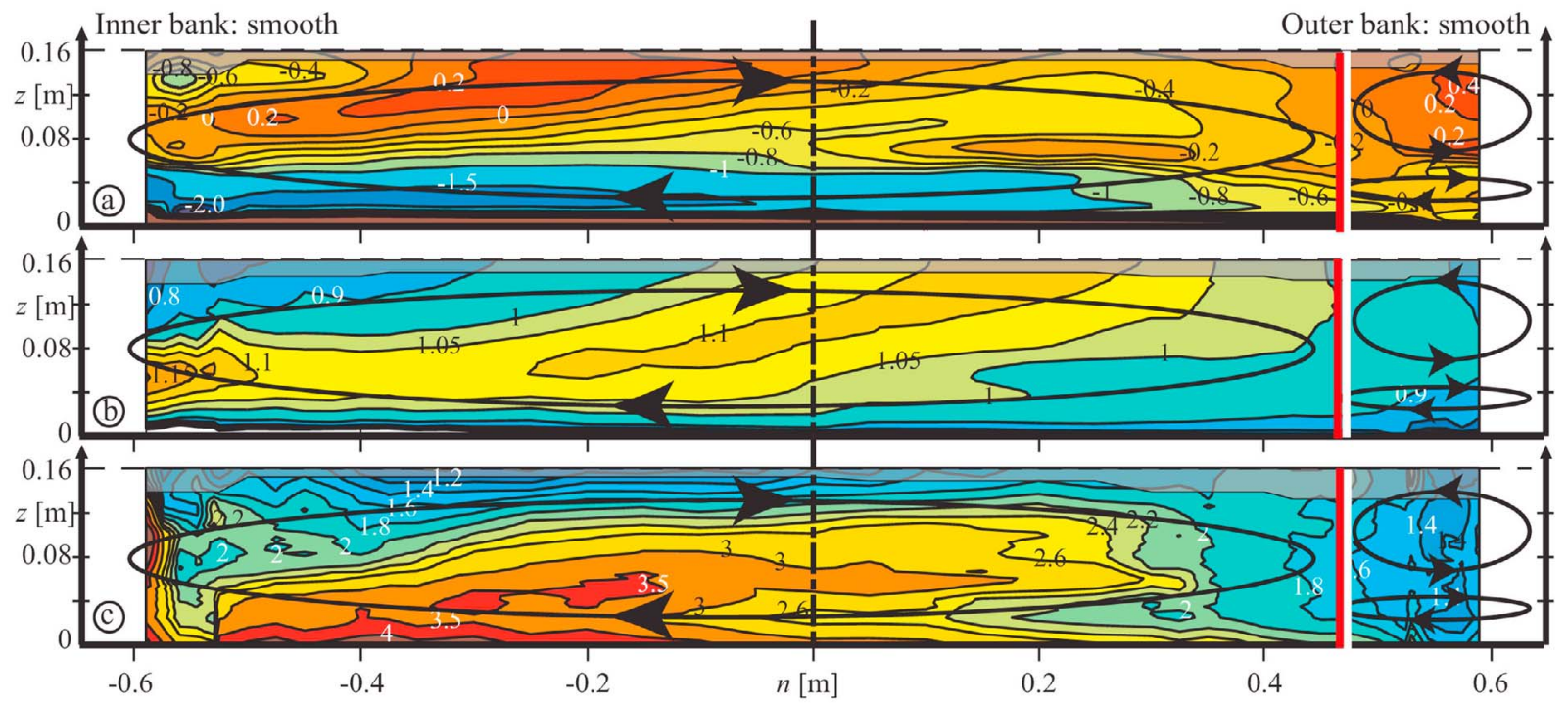

Figure 12. Isolines in the cross section at $150^{\circ}$ in the smooth-bank experiment of (a) the normalized streamwise vorticity $\omega_{s} H / U$, (b) the normalized streamwise velocity $v_{s} / U$, and (c) the normalized turbulent kinetic energy $k / u_{*, 0}^{2}$. Schematic pattern of center-region cell and outer-bank cell.

effective width from about $1.1 \mathrm{~m}$ to about $0.95 \mathrm{~m}$. This reduction in effective width by about $15 \%$ causes a corresponding increase in streamwise velocities of about $15 \%$ (Figure 4 for the cross section at $90^{\circ}$, and Figure $12 \mathrm{~b}$ versus Figure $13 \mathrm{~b}$ for the cross section at $150^{\circ}$ ). In typical natural channels with a bankfull aspect ratio of $B / H=20$ [Blanckaert, 2011], an outer-bank cell that is $2.3 \mathrm{H}$ wide would reduce the effective width by about $10 \%$ as compared to a situation without outer-bank cell, leading to a velocity increase of about $10 \%$. Because sediment transport formulae roughly scale with the cube of the velocity, this would cause an increase of sediment transport capacity by about $35 \%$. The outer-bank cell therefore causes a decrease of sediment transport capacity near the outer bank and an increase in the central part of the cross section, redistributing the downstream sediment flux [Clayton and Pitlick, 2007].

[39] The tke levels are rather low in the outer-bank boundary layer, and increase from the outer bank toward the edge of the outer-bank cell, as shown by the pattern of depth-averaged tke (Figure 2) and the patterns of tke in the cross sections at $90^{\circ}$ and $150^{\circ}$ (Figure 5 and Figures 12 and 13). An increase of outer-bank roughness considerably amplifies the maximum tke values at the edge of the outerbank cell, but it also shifts these maximum values farther away from the bank. The core of maximum the values is situated in the upper part of the water column, and therefore

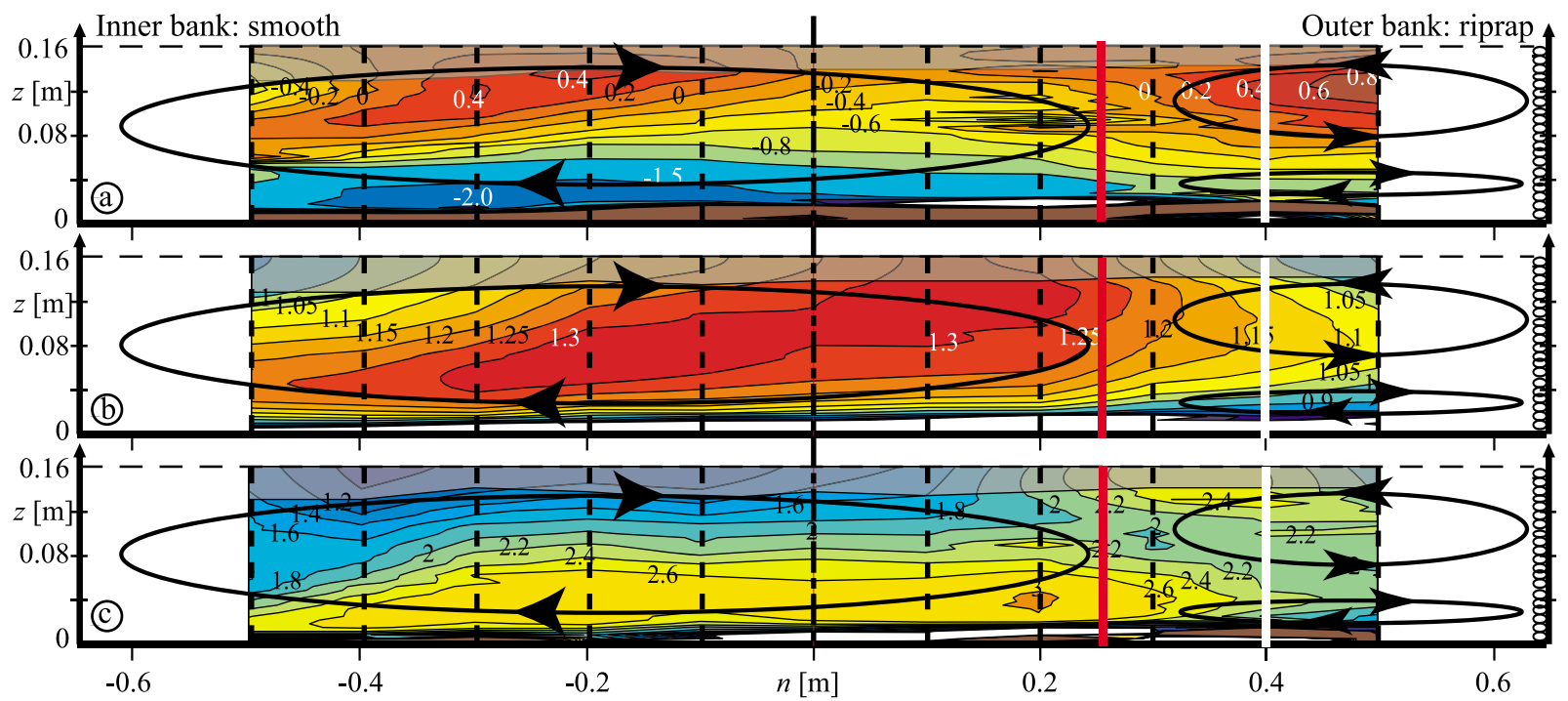

Figure 13. Isolines in the cross section at $150^{\circ}$ in the riprap-bank experiment of (a) the normalized streamwise vorticity $\omega_{s} H / U$, (b) the normalized streamwise velocity $v_{s} / U$, and (c) the normalized turbulent kinetic energy $k / u_{*, 0}^{2}$. Schematic pattern of center-region cell and outer-bank cell and indication of the measuring grid. 
not expected to be of dominant importance with respect to sediment transport.

[40] The incoming flow has a tendency to follow a straight path and to collide at an oblique angle with the outer bank. There, the flow turns against the outer bank, leading to vertical downwelling velocities that impinge on the bed. Frothingham and Rhoads [2003], Ferguson et al. [2003] and Blanckaert [2010] observed that maximum bed scour and bank erosion typically occur in this region where the incoming flow collides with the outer bank. In the reported experiments, this region is situated at about $60^{\circ}$ in the bend, which makes it coincide with the region where the width and the strength of the outer-bank cell reach their maximum values (Figures 9, 10, and 11), and hence the protective effect of the outer-bank cell also reaches its maximum effect. These results indicate that the evolution of the outer-bank cell around the bend may be morphologically relevant.

\subsection{Relevance of Laboratory Setup for Natural Rivers}

[41] The investigated schematized laboratory openchannel bend cannot be completely representative of the variety of configurations found in nature, which differ in geometric (planform and corresponding evolution of the radius of curvature, width, depth), sedimentologic (sediment size and gradation, stratigraphy) and hydraulic (Froude number, Reynolds number, inflow conditions, boundary roughness) characteristics. The reported experiments, however, were not intended to mimic the global hydrodynamic behavior in open-channel bends. Their objective was to isolate and accentuate the near-bank hydrodynamic processes that occur in natural curved open-channel reaches, and to investigate these processes at a level of detail that could not possibly be obtained in a field study. The following discussion relates the findings to natural rivers.

[42] The interaction of the flow with the mobile-bed topography is known to be of dominant importance with respect to the global hydrodynamic and morphodynamic behavior in alluvial channels. The flow, for example, is known to shift away from the shallow zones into the deep zones, which is commonly called topographic steering [Nelson, 1988; Blanckaert, 2010]. Previous experimental and numerical research in configurations with smooth-vertical banks [Blanckaert and de Vriend, 2004; van Balen et al., 2009, 2010] and the present experiments in configurations with rough banks indicate that the outer-bank cell is mainly due to the different influences that the water surface and the outer bank exert on the turbulence characteristics, implying that the configuration of the bed topography is not expected to play a dominant role. This hypothesis is in line with the observation of similar outer-bank cells in laboratory configurations with flat beds [e.g., Mockmore, 1943; Einstein and Harder, 1954; Rozovskii, 1957; see also, this paper], as well as laboratory configurations with mobile beds [Blanckaert and Graf, 2001; Jamieson et al., 2010; Termini and Piraino, 2011] and natural alluvial open-channel bends [e.g., Bathurst et al., 1977; Bridge and Jarvis, 1977; Bathurst et al., 1979; Thorne and Hey, 1979; de Vriend and Geldof, 1983; Clayton and Pitlick, 2007; Blanckaert et al., 2009].

[43] The flume's vertical banks may be representative of canalized river reaches, but they are not representative of most natural rivers, even though outer banks are typically steep in sharp meander bends [Leopold and Wolman, 1960;
Thorne et al., 1995]. The outer-bank cells observed here are similar to outer-bank cells observed in laboratory experiments with smooth or rough outer banks inclined at $30^{\circ}$ and $45^{\circ}$ [Duarte, 2008; Blanckaert, 2011] and in natural river bends with irregular geometry of the outer bank [e.g., Bathurst et al., 1977; Bridge and Jarvis, 1977; Bathurst et al., 1979; Thorne and Hey, 1979; de Vriend and Geldof, 1983; Clayton and Pitlick, 2007; Blanckaert et al., 2009]. This suggests that the configuration with vertical banks is relevant to investigate the outer-bank cell and the influence of the bank roughness. The results presented here point to the importance of the bank roughness, which is not straightforward to parameterize in natural open channels, because it is conditioned by factors such as vegetation and slump blocks produced by local bank erosion.

[44] Due to constraints in available laboratory space and minimum flow depth requirements to allow for accurate velocity measurements, laboratory flumes are typically less shallow than natural rivers. The reported experiments are characterized by $B / H=8.2$, which is considerably smaller than the typical value of about 20 in natural open channels at bankfull discharge [Blanckaert, 2011]. The value is representative, however, for the deepest outer half of the cross section in alluvial open-channel bends where the major part of the flow is conveyed. The results presented here indicate that the outer-bank cell is primarily determined by the characteristics near the bank: its strength depends on the outer-bank roughness and its size scales with the flow depth near the bank. Hence the shallowness of the flow is not expected to be a dominant control parameter on the flow processes near the outer bank. Moreover, the flume was sufficiently large to avoid interference of the outer-bank cell with influences from the inner bank.

[45] The uniform flow over the width at the entry of the laboratory flume is not representative of natural open-channel bends, where the inflow conditions are mainly determined by the upstream river planform. Periodic meanders with alternating bends typically lead to a velocity decrease from the inner toward the outer bank at the bend entry. But the variety of river planforms may give rise to other velocity distributions at the entry. The flume's centerline radius of curvature is discontinuous at the bend entry and exit in the laboratory flume, and constant around the bend, which is not representative for natural curved open channels. Due to inertia, however, the flow adapts in a more gradual way to these imposed abrupt changes in curvature. Moreover, abrupt breaks, peaks and changes tend to be common features in natural meanders, as for example on the Embarras River investigated by Frothingham and Rhoads [2003]. Therefore, the first part of the laboratory bend is representative of zones of pronounced curvature increase in open-channel bends, and the middle part of the bend is representative of zones of weak curvature variation. The results presented here indicate that the outer-bank cell is primarily determined by the characteristics near the bank, and not by the inflow conditions at the bend entry or the planform.

\subsection{Generalization of Results}

[46] The experimental study in a schematized laboratory configuration is a first, but an essential step in a combined experimental-numerical methodology that aims at gaining insight into the relevant near-bank processes, and ultimately 
translating them into applicable tools, and especially in an improved parameterization of the flow forcing on the bank in morphological models.

[47] Blanckaert and de Vriend [2004] have shown that the accurate simulation of the outer-bank cell requires $3 \mathrm{D}$ numerical models with a turbulence closure that can account for the transfer of kinetic energy from the turbulence to the mean flow (see equation (6)). van Balen et al. [2010] simulated the outer-bank cell in the here-reported smooth bank experiment by means of large-eddy simulations. The numerical simulations provide information on variables that are difficult to measure experimentally but of dominant importance with respect to the flow forcing on the bank, such as the bank shear stress and the pressure fluctuations acting on the bank [van Balen et al., 2010; Constantinescu et al., 2011a; Kang and Sotiropoulos, 2011]. As mentioned in the introduction, the extension of numerical research to configurations with rough banks is not straightforward and requires a validation of the numerical model by means of experimental data. The results of the experiments described here fill a useful place in the list of required benchmark cases.

[48] Even though a validated 3D hydrodynamic model would be able to resolve all relevant hydrodynamic processes, depth-integrated 2D models will remain an important tool for the investigation of large-scale and/or long-term morphodynamic problems in real rivers due to limitations in computational capacity. This means that an upscaling and/or parameterization of the flow forcing on the bank is required, which can be based on the combined experimental-numerical research. First, the investigated parameter space can be broadened by means of the validated numerical model, by investigating different planforms and roughness configurations. Second, an empirical parameterization can be derived for the flow forcing on the bank as a function of the dominant control parameters.

\section{Conclusions}

[49] This paper investigated near-bank hydrodynamic processes occurring in curved open-channel reaches by means of experiments in a schematized laboratory configuration with transversally horizontal sand bed. The inner bank was vertical and smooth, whereas three different roughness configurations of the vertical outer bank were investigated: $\mathrm{PVC}$, sand and riprap, which are smoother, equally rough and rougher than the sand bed, respectively. These experiments extended foregoing research on the near-bank processes that was limited to configurations with smooth vertical banks that may not be representative of natural rives.

[50] Besides the curvature-induced center-region cell of secondary flow that is typical for curved open-channel flow, an outer-bank cell of reversed secondary flow occurred for all the investigated roughness configurations of the outer bank (Figures 3 and 9). Momentum transport away from the bank by the outer-bank cell widened the outer-bank boundary layer, which caused a decrease of the streamwise velocity toward the bank in the region covered by the outerbank cell, and hence tended to reduce the flow forcing on the bank. But the outer-bank cell also advected high-momentum fluid originating from near the water surface toward the lower part of the outer bank (Figure 4), which tended to increase the flow forcing on the bank. A core of high tke occurred at the separation between both cells of secondary flow (Figure 5). The high-tke core occurred in the upper part of the water column, and is therefore not expected to play a dominant role with respect to morphological processes. Increasing the roughness of the outer bank caused a considerable widening of the outer-bank cell and the outer-bank boundary layer, but also strengthened the outer-bank cell and its advection of high-momentum fluid (Figure 4). The widening of the outer-bank boundary layer induced by the outer-bank cell reduced the effective width of the channel, i.e., the width where most of the discharge is conveyed. In typical natural channels with steep and rough outer banks, this reduction in effective width causes an increase in sediment transport capacity in the central part of the channel, leading to higher transport rates per unit width.

[51] For all roughness configurations, the near-bank processes were qualitatively similar all around the bend, but showed considerable quantitative variations (Figure 9). The outer-bank cell amplified in the first part of the bend, and its width and strength reached maximum values at around $60^{\circ}$ in the bend (Figures 9, 10, and 11), which coincided with the location that is most vulnerable to bed scour and bank erosion. This indicates that the variations of the near-bank processes and the outer-bank cell around the bend are morphologically relevant. Downstream of the bend apex, the outer-bank cell's width and strength remained about constant (Figures 9, 10, and 11).

[52] For all investigated roughness configurations, the outer-bank cell was mainly generated by centrifugal effects related to the deformation of the vertical profiles of the streamwise velocity. Moreover the outer-bank cell and the deformed velocity profiles enhanced each other. These favorable centrifugal effects were balanced by terms related to the anisotropy of the cross-stream turbulence. Increasing the outer-bank roughness amplified all dominant mechanisms with respect to the generation of the outer bank, without modifying their relative importance (Figures 7 and 8).

[53] Acknowledgments. The reported research was funded by the Swiss National Science Foundation under grants SNF 20020-103932 and SNF 200020-119835/1. The first author was partially supported by the Chinese Academy of Sciences Visiting Professorship for Senior International Scientists, grant number 2011T2Z24, and by the Sino-Swiss Science and Technology Cooperation for the Institutional Partnership Project, grant number IP13_092911.

\section{References}

Bathurst, J. C., C. R. Thorne, and R. D. Hey (1977), Direct measurements of secondary currents in river bends, Nature, 269, 504-506, doi: $10.1038 / 269504 \mathrm{a} 0$.

Bathurst, J. C., C. R. Thorne, and R. D. Hey (1979), Secondary flow and shear stress at river bends, J. Hydraul. Div. Am. Soc. Civ. Eng., 105(10), $1277-1295$.

Blanckaert, K. (2009), Saturation of curvature-induced secondary flow, energy losses, and turbulence in sharp open-channel bends: Laboratory experiments, analysis, and modeling, J. Geophys. Res., 114, F03015, doi:10.1029/2008JF001137.

Blanckaert, K. (2010), Topographic steering, flow recirculation, velocity redistribution and bed topography in sharp meander bends, Water Resour. Res., 46, W09506, doi:10.1029/2009WR008303.

Blanckaert, K. (2011), Hydrodynamic processes in sharply curved river bends and their morphological implications, J. Geophys. Res., 116, F01003, doi:10.1029/2010JF001806. 
Blanckaert, K., and H. J. de Vriend (2003), Nonlinear modeling of mean flow redistribution in curved open channels, Water Resour. Res., 39(12), 1375, doi:10.1029/2003WR002068

Blanckaert, K., and H. J. de Vriend (2004), Secondary flow in sharp open-channel bends, J. Fluid Mech., 498, 353-380, doi:10.1017/ S0022112003006979.

Blanckaert, K., and H. J. de Vriend (2010), Meander dynamics: A nonlinear model without curvature restrictions for flow in open-channel bends, J. Geophys. Res., 115, F04011, doi:10.1029/2009JF001301.

Blanckaert, K., and W. H. Graf (2001), Mean flow and turbulence in openchannel bend, J. Hydraul. Eng., 127(10), 835-847, doi:10.1061/(ASCE) 0733-9429(2001)127:10(835).

Blanckaert, K., and W. H. Graf (2004), Momentum transport in sharp openchannel bends, J. Hydraul. Eng., 130(3), 186-198, doi:10.1061/(ASCE) 0733-9429(2004)130:3(186).

Blanckaert, K., and U. Lemmin (2006), Means of noise reduction in acoustic turbulence measurements, J. Hydraul. Res., 44(1), 3-17, doi:10.1080 00221686.2006 .9521657

Blanckaert, K., I. Schnauder, A. Sukhodolov, van Balen, and W. S. J. Uijttewaal (2009), Meandering: Field experiments, laboratory experiments and numerical modeling, paper presented at 6th Symposium on River, Coastal and Estuarine Morphodynamics (RCEM), Int. Assoc. on Hydraul. Eng. and Res., Santa Fe, Argentina, 21-25 Sept.

Booij, R. (2003), Measurements and large eddy simulations of the flows in some curved flumes, J. Turbul., 4(8), 1-17, doi:10.1088/1468-5248/4/1/008

Bridge, J. S., and J. Jarvis (1977), Velocity profiles and bed shear stress over various bed configurations in a river bend, Earth Surf. Processes Landforms, 2, 281-294, doi:10.1002/esp.3290020402.

Chang, W. Y., G. Constantinescu, W. F. Tsai, and H. C. Lien (2011), Coherent structure dynamics and sediment erosion mechanisms around an in-stream rectangular cylinder at low and moderate angles of attack, Water Resour. Res., 47, W12532, doi:10.1029/2011WR010586.

Clayton, J. A., and J. Pitlick (2007), Spatial and temporal variations in bed load transport intensity in a gravel bed river bend, Water Resour. Res., 43 W02426, doi:10.1029/2006WR005253.

Constantinescu, G., M. Koken, and J. Zeng (2011a), The structure of turbulent flow in an open channel bend of strong curvature with deformed bed Insight provided by detached eddy simulation, Water Resour. Res., 47, W05515, doi:10.1029/2010WR010114.

Constantinescu, G. S., S. Miyawaki, B. Rhoads, A. Sukhodolov, and G. Kirkil (2011b), Structure of turbulent flow at a river confluence with momentum and velocity ratios close to 1 : Insights from an eddy-resolving numerical simulation, Water Resour. Res., 47, W05507, doi:10.1029/ 2010WR010018.

Crosato, A. (2008), Analysis and modelling of river meandering, PhD dissertation, Delft Univ. of Technol., Delft, Netherlands.

Darby, S. E., and C. R. Thorne (1996), Development and testing of riverbank-stability analysis, J. Hydraul. Eng., 122(8), 443-454, doi:10.1061 (ASCE)0733-9429(1996)122:8(443).

de Vriend, H. J., and H. J. Geldof (1983), Main flow velocity in short and sharply curved river bends, Rep. 83-6, Lab. Fluid Mech., Dep. Civ Eng., Delft Univ. Technol., Delft, Netherlands.

Duarte, A. (2008), An experimental study on main flow, secondary flow and turbulence in open-channel bends with emphasis on their interaction with the outer-bank geometry, $\mathrm{PhD}$ thesis 4227, École Polytech. Fed. de Lausanne, Lausanne, Switzerland.

Einstein, H. A., and J. A. Harder (1954), Velocity distribution and the boundary layer at channel bends, Eos Trans. AGU, 35(1), 114-120.

Ferguson, R. I., D. R. Parsons, S. N. Lane, and R. J. Hardy (2003), Flow in meander bends with recirculation at the inner bank, Water Resour. Res., 39(11), 1322, doi:10.1029/2003WR001965.

Frothingham, K. M., and B. L. Rhoads (2003), Three-dimensional flow structure and channel change in an asymmetrical compound meande loop, Embarras River, Illinois, Earth Surf. Processes Landforms, 28 625-644, doi:10.1002/esp.471.

Hardy, R. J., S. N. Lane, R. I. Ferguson, and D. R. Parsons (2007) Emergence of coherent flow structures over a gravel surface: A numerical experiment, Water Resour. Res., 43, W03422, doi:10.1029/ 2006WR004936.

Hickin, E. J. (1974), The development of meanders in natural river channels, Am. J. Sci., 274, 414-442, doi:10.2475/ajs.274.4.414.

Hinze, J. O. (1975), Turbulence, McGraw-Hill, New York.

Hooke, J. (2003), River meander behaviour and instability: A framework for analyses, Trans. Inst. Br. Geogr., 28(2), 238-253, doi:10.1111/ 1475-5661.00089.

Hurther, D., and U. Lemmin (1998), A constant-beam-width transducer for 3D acoustic Doppler profile measurements in open-channel flows, Meas. Sci. Technol., 9, 1706-1714, doi:10.1088/0957-0233/9/10/010.
Ikeda, S., G. Parker, and K. Sawai (1981), Bend theory of river meanders: Part 1. Linear development, J. Fluid Mech., 112, 363-377, doi:10.1017/ S0022112081000451

Jamieson, E. C., G. Post, and C. D. Rennie (2010), Spatial variability of three-dimensional Reynolds stresses in a developing channel bend, Earth Surf. Processes Landforms, 35, 1029-1043, doi:10.1002/esp.1930.

Jin, Y. C., P. M. Steffler, and F. E. Hicks (1990), Roughness effects on flow and shear-stress near outside bank of curved channel, J. Hydraul. Eng., 116(4), 563-577, doi:10.1061/(ASCE)0733-9429(1990)116:4(563).

Johannesson, H., and G. Parker (1989), Velocity redistribution in meandering rivers, J. Hydraul. Eng., 115(8), 1019-1039, doi:10.1061/(ASCE) 0733-9429(1989)115:8(1019).

Kang, S., and F. Sotiropoulos (2011), Flow phenomena and mechanisms in a field-scale experimental meandering stream with a pool-riffle sequence: Insight gained via numerical simulation, J. Geophys. Res., 116, F03011, doi:10.1029/2010JF001814.

Keylock, C. J., R. J. Hardy, D. R. Parsons, R. I. Ferguson, S. N. Lane, and K. S. Richards (2005), The theoretical foundations and potential for large-eddy simulation (LES) in fluvial geomorphic and sedimentological research, Earth Sci. Rev., 71(3-4), 271-304, doi:10.1016/j.earscirev. 2005.03.001

Koken, M., and G. Constantinescu (2011), Flow and turbulence structure around a spur dike in a channel with a large scour hole, Water Resour. Res., 47, W12511, doi:10.1029/2011WR010710.

Lemmin, U., and T. Rolland (1997), Acoustic velocity profiler for laboratory and field studies, J. Hydraul. Eng., 123(12), 1089-1098, doi:10.1061/ (ASCE)0733-9429(1997)123:12(1089).

Leopold, L. B., and M. G. Wolman (1960), River meanders, Geol. Soc. Am. Bull., 71, 769-794, doi:10.1130/0016-7606(1960)71[769:RM]2.0. $\mathrm{CO} ; 2$.

Markham, A. J., and C. R. Thorne (1992), Geomorphology of gravel-bed river bends, in Dynamics of Gravel-Bed Rivers, edited by P. Billi et al., pp. 433-456, John Wiley, Chichester, U. K.

McCoy, A., G. Constantinescu, and L. Weber (2007), A numerical investigation of coherent structures and mass exchange processes in channel flow with two lateral submerged groynes, Water Resour. Res., 43, W05445, doi:10.1029/2006WR005267.

Mockmore, C. A. (1943), Flow around bends in stable channels, Trans. Am. Soc. Civ. Eng., 109, 593-628.

Nelson, J. E. (1988), Mechanics of flow and sediment transport over nonuniform erodible beds, PhD dissertation, 277 pp., Univ. of Wash., Seattle.

Nezu, I., and H. Nakagawa (1993), Turbulence in Open Channel Flows, A. A. Balkema, Rotterdam, Netherlands.

Patel, V. C. (1998), Perspective: Flow at high Reynolds number and over rough surfaces-Achilles heel of CFD, J. Fluids Eng., 120, 434-444, doi:10.1115/1.2820682.

Rinaldi, M., and S. E. Darby (2005), Advances in modeling river bank erosion processes, paper presented at 6th International Gravel Bed Rivers Workshop, IAHR, Linz, Austria.

Rinaldi, M., B. Mengoni, L. Luppi, S. E. Darby, and E. Mosselman (2008), Numerical simulation of hydrodynamics and bank erosion in a river bend, Water Resour. Res., 44, W09428, doi:10.1029/2008WR007008.

Rozovskii, I. L. (1957), Flow of Water in Bends of Open Channels [in Russian], Acad. of Sci. of the Ukrainian SSR, Kiev. [English translation, Isr. Program for Sci. Transl., Jerusalem, 1961.]

Simon, A., A. Curini, S. E. Darby, and E. J. Langendoen (2000), Bank and near-bank processes in an incised channel, Geomorphology, 35(3-4), 193-217, doi:10.1016/S0169-555X(00)00036-2.

Stoesser, T. (2010), Physically realistic roughness closure scheme to simulate turbulent channel flow over rough beds within the framework of LES, J. Hydraul. Eng., 136(10), 812-819, doi:10.1061/(ASCE)HY.19437900.0000236 .

Stoesser, T., and W. Rodi (2004), Large eddy simulation of flow over rough channel beds, paper presented at BAW Workshop Soil and Bed Stability - Interaction Effects Between Geotechnics and Hydraulic Engineering, Bundesanst. für Wasserbau, Karlsruhe, Germany, 17 Sept.

Stoesser, T., C. Braun, M. Garcia-Villalba, and W. Rodi (2008), Turbulence structures in flow over two-dimensional dunes, J. Hydraul. Eng., 134(1), 42-55, doi:10.1061/(ASCE)0733-9429(2008)134:1(42).

Stoesser, T., N. Rüther, and N. R. B. Olsen (2010), Calculation of primary and secondary flow and boundary shear stresses in a meandering channel, Adv. Water Resour., 33(2), 158-170, doi:10.1016/j.advwatres.2009. 11.001 .

Termini, D., and M. Piraino (2011), Experimental analysis of crosssectional flow motion in a large amplitude meandering bend, Earth Surf Processes Landforms, 36, 244-256, doi:10.1002/esp.2095.

Thorne, C. R. (1982), Processes and mechanisms of river bank erosion, in Gravel-Bed Rivers, edited by R. D. Hey et al., pp. 227-259, John Wiley, New York. 
Thorne, C. R., and R. D. Hey (1979), Direct measurements of secondary currents at a river inflexion point, Nature, 280, 226-228, doi:10.1038/ $280226 \mathrm{a} 0$

Thorne, C. R., S. R. Abt, and S. T. Maynord (1995), Prediction of nearbank velocity and scour depth in meander bends for design of riprap revetments, in River, Coastal and Shoreline Protection: Erosion Control Using Riprap and Armourstone, edited by C. R. Thorne et al., pp. 115-133, John Wiley, Chichester, U. K.

Thorne, S. D., and D. J. Furbish (1995), Influences of coarse bank roughness on flow within a sharply curved fiver bend, Geomorphology, 12 , 241-257, doi:10.1016/0169-555X(95)00007-R van Balen, W., W. S. J. Uijttewaal, and K. Blanckaert (2009), Large-eddy simulation of a mildly curved open-channel flow, J. Fluid Mech., 630, 413-442, doi:10.1017/S0022112009007277.

van Balen, W., K. Blanckaert, and W. S. J. Uijttewaal (2010), Analysis of the role of turbulence in curved open-channel flow at different water depths by means of experiments, LES and RANS, J. Turbul., 11, 1-34, doi:10.1080/14685241003789404.

Van Prooijen, B. C., and J. C. Winterwerp (2010), A stochastic formulation for erosion of cohesive sediments, J. Geophys. Res., 115, C01005, doi:10.1029/2008JC005189.

Zeng, J., G. Constantinescu, K. Blanckaert, and L. Weber (2008), Flow and bathymetry in sharp open channel bends: Experiments and predictions, Water Resour. Res., 44, W09401, doi:10.1029/2007WR006303. 